\title{
Blinding Struts - Part 2: Towards A Simplified Design Method
}

\author{
Vollum, R.L., Izzuddin, B.A. , Abela, J.M., \& Potts, D.M.
}

Department of Civil and Environmental Engineering

Imperial College London, London SW7 2AZ, United Kingdom

\begin{abstract}
The companion paper described how concrete blinding can be used to prop retaining walls in cut and cover excavations prior to the completion of the base slab. In addition, it was demonstrated that the behaviour of blinding struts can be accurately predicted with nonlinear finite element analysis (NLFEA) if the strut properties and ground profile are known. This paper presents a simple designoriented analytical model which can be used for blinding struts as an alternative to NLFEA. The simplified model is shown to give comparable results to NLFEA and is attractive for design since it allows the effect of variations in imperfection amplitude and length to be rapidly assessed. A case study is presented which illustrates the use of the method and demonstrates that relatively thin blinding struts can resist the maximum axial forces likely to be encountered in cut and cover excavations.
\end{abstract}

Keywords: Upheaval buckling; geometric imperfections; concrete; cut and cover excavations; nonlinear finite element analysis; structural design 


\section{Introduction}

The companion paper [1] shows that blinding struts fail in upheaval buckling and that the critical buckling load can be accurately predicted with NLFEA if the strut properties and ground profile are known. This paper presents a simplified design oriented analytical method for the design of blinding struts which are cast onto geometrical imperfections arising from lack of ground flatness. The model gives useful insights into the effect of changes in the length and amplitude of the geometric imperfection. The method is an enhancement of Croll's [2,3] clamped column analogy for upheaval buckling which is discussed in the companion paper [1].

Croll's $[2,3]$ analysis is restricted to cases where the length of the foundation imperfection $L_{g}$ is greater than or equal to the empathetic length $L_{p o}$ which is given by:

$L_{p o}=\sqrt[4]{\frac{384 E / w_{g}}{q}}$

where $E$ is the elastic modulus, $I$ is the second moment of area, $w_{g}$ is the imperfection amplitude and $q$ is the self-weight of the strut per unit length.

In contrast to Croll's model, the model proposed in this paper is applicable to blinding struts where i) the buckle length is limited by the excavation width $\left(L_{e x c}\right)$, ii) end conditions can significantly affect the buckling load, iii) the imperfection length is typically shorter than the empathetic wavelength, and iv) failure can occur due to either elastic buckling or concrete crushing allowing for tensile cracking. 


\section{Research Scope}

The companion paper [1] shows that the strength and failure mode of blinding struts depends on factors including the amplitude of the ground imperfection, the eccentricity of the line of thrust at the ends of the strut and the degree of rotational restraint provided by the retaining wall. This paper develops a design-oriented analytical model for predicting the short-term failure load of blinding struts which are cast onto ground imperfections arising from lack of flatness. Fig. 20 in the companion paper [1] shows that sinusoidal imperfections can be critical for relatively thin struts whereas parabolic profiles with $\left(L_{g}=L_{e x c}\right)$ can be critical for thicker struts. Consequently, this paper assumes the ground profile to be either i) parabolic with length equal to the excavation width $\left(L_{e x c}\right)$ or ii) sinusoidal with $L_{g} \leq \min \left(L_{p o}, L_{e x c}\right)$. The ICFEP ground heave profile [1] is not considered in this paper since it can be modelled with an equivalent parabolic imperfection for practical purposes. The model simplifies the design of blinding struts by conservatively assuming that the retaining walls offer no rotational restraint and that the strut is loaded at its centroid. The ends of the blinding strut are assumed to be prevented from lifting by the inwards rotation of the retaining wall, as observed in the geotechnical analysis (see Fig. 1). Importantly, failure is assumed to be governed by either elastic buckling or material failure at the centre of the buckle wavelength. The NLFEA described in this paper was carried out with ADAPTIC [6,7] following the procedure described in the companion paper [1]. The effects of ground heave and concrete creep occurring after casting of the slab are not examined in this paper but need to be considered in design. Incremental ground heave, subsequent to the casting of the slab, is assumed to be less critical than geometrical imperfections of the same size and shape arising 
from lack of flatness for reasons discussed in the companion paper [1]. Load tests and numerical analysis [4] show that creep is unlikely to reduce the failure load of blinding struts with working loads less than half their short-term failure load, which is likely to be the case when load and material safety factors are taken into account.

\section{Development of design-oriented model}

The proposed simplified analytical model is based on the following assumptions (see Fig. 2):

- The concrete is linearly elastic in compression with no tensile resistance.

- The strut is assumed to be prismatic in section. This is an idealisation since, in reality, the top surface of the blinding strut is likely to be relatively flat when cast, with the strut thickness varying due to the presence of ground imperfections.

- The strut is assumed to be unstressed when laid over the geometrical imperfection since this gives the least critical elastic buckling load [1-3].

- The buckle propagation length $L_{p}$ cannot exceed the excavation width $L_{\text {exc }}$, with $L_{g} \leq L_{p} \leq \min \left(2 d_{e x c}^{-}, 2 d_{e x c}^{+}\right) \leq L_{e x c}$ where $d_{e x c}^{-}$and $d_{e x c}^{+}$are the distances from the centre of the imperfection to the left and right retaining walls as defined in Fig. 2. This renders the model insensitive to the presence of rotational restraint at the strut ends.

- The ground profile is assumed to be either i) parabolic with length equal to the excavation width or ii) sinusoidal with $L_{g} \leq \min \left(L_{p o}, L_{e x c}\right)$. 


\subsection{Case 1: Parabolic imperfection with amplitude $\mathbf{w}_{\mathrm{g}}$ and length $L_{\text {exc }}$}

The critical buckling load $\mathrm{P}_{\mathrm{b}}$ for a strut cast onto a parabolic imperfection with length $L_{\text {exc }}$ and amplitude $w_{g}$ equals the lift off load $P_{L}$ which is given by:

$$
P_{L}=\frac{q L_{e x c}^{2}}{8 w_{g}}
$$

The design load should not exceed the crushing load which equals $f_{c d} h \mathrm{kN} / \mathrm{m}$ where $f_{c d}$ is the design concrete strength in $\mathrm{MPa}$ and $h$ is the strut thickness in metres.

\subsection{Case 2: Sinusoidal imperfection with $L_{g} \leq \min \left(L_{p o}, L_{e x c}\right)$.}

Fig. 2a illustrates the change in buckle shape with increasing axial load for a blinding strut cast over a sinusoidal imperfection of length $L_{g}$, where $L_{g}$ is less than the empathetic length $L_{p o}$. It is convenient to transform the actual imperfection of amplitude $w_{g}$ and length $L_{g}$ into an equivalent imperfection of length $L_{p}$, as shown in Fig. $2 \mathrm{~b}$, where $L_{p}$ is the propagating buckle length. Using modal decomposition concepts for column buckling under fixed end conditions, the actual imperfection can be expressed as a weighted sum of modal components. In the present context, the component of the first buckling mode is of most relevance, and this can be determined from the orthogonality condition of the buckling modes with respect to the geometric stiffness that can be easily established using a rotational spring analogy [5]. Accordingly, the amplitude of the equivalent imperfection of length $L_{p}$ is obtained from the first modal component as:

$w_{g}^{\prime}=\omega w_{g}$

where: 
$\omega=\frac{2 \sin (\tau \gamma)}{\pi\left(1-\gamma^{2}\right)}$

with:

$\gamma=\frac{L_{g}}{L_{p}}$

As shown in the Appendix, the propagating buckle load $P_{p}$ is given by:

$P_{p}=\frac{2 \beta}{1+\beta} \frac{4 \pi^{2} E I}{L_{p}^{2}}$

where:

$\beta=\frac{\beta_{g}}{\omega \gamma^{4}}$

$\beta_{g}=\frac{q L_{g}^{4}}{384 E / w_{g}} \leq 1, \quad L_{g} \leq \min \left(R d_{e x c}^{-}, 2 d_{e x c}^{+}\right)$

The critical buckling load $P_{b}$ is the maximum load given by equation (6) with increasing buckle length $L_{p}$ in the range $L_{g} \leq L_{p} \leq \min \left(2 d_{e x c}^{-}, 2 d_{e x c}^{+}\right)$. The transverse displacement of the equivalent strut including the equivalent imperfection is given by:

$w^{\prime}=(1+\beta) w_{g}{ }^{\prime}$

The overall amplitude of the actual buckle is therefore given by:

$w=w^{\prime}+w_{g}-w_{g}^{\prime}=w_{g}(1+\beta \omega)$

The hogging bending moment at the centre of the buckle is obtained from moment equilibrium as:

$M=P_{p} w-\frac{q L_{p}^{2}}{8}$ 


\subsection{Calculation of stress at centre of buckle}

The effects of concrete cracking and crushing need to be accounted for in the design of blinding struts, as these may fail due to material failure before reaching the critical elastic buckling load given by equation (6). The concrete tensile strength is uncertain in practice and is usually neglected in the design of concrete structures at the ultimate limit state. Fig. 3 shows the variation in stress over the cross section of a strut that is linear elastic in compression with no tensile resistance for loading eccentricities $(e=M / P)$ of $h / 6, h / 3$ and $h / 2$. Before tensile cracking, the extreme fibre stresses are given by:

$e \leq \frac{h}{6} \Rightarrow \sigma_{c}=\frac{P_{p}}{h}\left(1 \pm \frac{6 e}{h}\right)$

After cracking, the compressive stress in the bottom fibre of the section varies with $e$ as follows:

$\frac{h}{6} \leq e \leq \frac{h}{2} \Rightarrow \sigma_{c}=\frac{4 P_{p}}{3(h-2 e)}$

where $e$ is the eccentricity of the line of thrust below the strut centroid which is given by:

$$
e=M / P_{p}=w-\frac{q L_{p}^{2}}{8 P_{p}}
$$

\section{Failure Criteria}

This section examines two alternative material based failure criteria for blinding struts. Failure is assumed to occur firstly when the concrete cracks at the centre of the buckle, and secondly when the concrete first crushes. 


\section{1 "No tension" design criterion}

Equation (12) can be used in conjunction with equations (4) to (10) and (14) to determine the buckle propagation length $L_{p}$, and hence load, at which the stress equals zero in the top fibre at the centre of the buckle. Alternatively, it can be shown that the "no tension" normalised imperfection amplitude $\omega^{*}$ at which the stress equals zero in the top fibre at the centre of the buckle is given by:

$$
\omega^{*}=\frac{\beta_{g}}{\gamma^{4}}\left(\frac{\pi^{2}}{6}-1\right)+\frac{\pi^{2}}{6}\left(1-\frac{h}{6 w_{g}}\right)
$$

The buckle length corresponding to "no tension" can be found by equating equation (15) for $\omega^{*}$ to equation (4) for $\omega$ and solving numerically for $\gamma$. The "no tension" buckling load can then be calculated with equation (6).

\subsection{Concrete crushing failure criterion}

Concrete crushing is also investigated as an alternative design failure criterion. The extreme fibre stress is calculated for an uncracked/cracked section with equation (12) or (13) as appropriate in terms of the loading eccentricity at the centre of the buckle. Failure is assumed to occur when the extreme fibre stress equals the design concrete strength at the centre of the buckle. Theoretically, the loading eccentricity can increase up to $e=h / 2$ for a cracked strut with infinite compressive strength. The estimate of the compressive stress is approximate after cracking since the buckling load reduces somewhat due to the local reduction in flexural rigidity which is not accounted for in the method. 


\subsection{Calibration of the analytical model}

The accuracy of the analytical model was investigated numerically with NLFEA for a range of geometric imperfections with $0.1 \leq L_{g} / L_{p o} \leq 1$ [4]. The concrete was modelled with Model 1 from Table 1, which should be read in conjunction with Fig. 5 in the companion paper [1], which is linearly elastic in tension and compression as assumed in the analytical model. Table 2 shows the results for a typical case study in which $E=28 \mathrm{GPa}, L_{g}=2650 \mathrm{~mm}, h=360 \mathrm{~mm}, w_{g}=100 \mathrm{~mm}, P_{c o}=6179 \mathrm{kN} / \mathrm{m}$ and $L_{g} / L_{p o}=0.10$. Table 2 shows that the analytical model accurately predicts the critical buckling load but it significantly overestimates the "no tension load". Fig. 4 examines the reasons for this by comparing the values given by the analytical method and NLFEA for i) the buckle amplitude (Fig. 4a), ii) the extreme fibre stresses at the centre of the buckle (Figs. $4 \mathrm{~b}$ to $4 \mathrm{c}$ ), and iii) the buckle length (Fig. 4d). Fig. 4a shows that the analytical model accurately predicts the critical buckling load but slightly underestimates the buckle amplitude. Figs. 4b and 4c show that the analytical model underestimates the tensile stress in the top fibre at the centre of the buckle and consequently overestimates the "no tension" load. Fig. 4d shows that the analytical model tends to overestimate the buckle length with the overestimate depending on the buckle propagation load. Consideration of equation (11) shows that the tensile stress is underestimated at the centre of the buckle as a result of the buckle amplitude being slightly underestimated and the buckle length being overestimated. Underestimating the buckle amplitude leads to the hogging moment $M=P_{p} w$ being underestimated whereas overestimating the buckle length leads to the sagging moment due self-weight $\left(M=q L_{p}{ }^{2} / 8\right)$ being overestimated. Consequently, the "no 
tension load" is overestimated. Analysis shows that equation (16) below predicts the loading eccentricity more accurately than equation (14):

$e=M / P_{p}=w-\frac{c q L_{p}^{2}}{8 P_{p}}$

where the coefficient $c$ corrects for the overestimate in the length of the equivalent imperfection and $w$ is given by equation (10). Parametric analyses [4] show that $c$ can be taken as 0.8 for design purposes. Equation (15) for the "no tension" normalised imperfection amplitude $\omega^{*}$ needs to be modified as follows when $e$ is calculated with equation (16):

$\omega^{*}=\frac{\beta_{g}}{\gamma^{4}}\left(\frac{\pi^{2}}{6 c}-1\right)+\frac{\pi^{2}}{6 c}\left(1-\frac{h}{6 w_{g}}\right)$

Figs. $5 a$ and $5 b$ show that the extreme fibre tensile stresses calculated with $e$ from equation (16) compare reasonably well with the stresses given by NLFEA for the strut considered in Fig. 4.

\subsection{Verification of analytical method and evaluation of failure criteria}

This section evaluates the proposed analytical model with $e$ calculated from equation (16) by comparing its predictions with those given by NLFEA. The NLFEA analyses were carried out with concrete material models 1 to 4 in Table 1 to investigate the influences of concrete cracking and nonlinearity in compression on the failure load. Model 1 is linearly elastic in both compression and tension. Model 2 is linearly elastic in compression with no tensile resistance. Model 3 is linearly elastic in compression to $f_{c}{ }^{\prime}$ and in tension to $f_{t}$ after which the concrete softens linearly in both tension and compression as described in the companion paper [1]. Model 4 is 
similar to Model 3, but the compressive stress-strain curve is nonlinear as illustrated in Fig 5 of the companion paper [1]. In the case of Models 1 to 3, concrete crushing was assumed to occur in the blinding strut when the extreme fibre stress, calculated with equation (12) or (13) as appropriate, reached the concrete strength. The geometrical properties of the analysed struts are listed in Table 3. The response of these struts was determined with i) the analytical model and ii) NLFEA using each of the four concrete material models described in Table 1.

\subsubsection{Case study 1: Short imperfection with $L_{g} / L_{p o}=0.1: f_{c}{ }^{\prime}=30 \mathrm{MPa}$}

Table 4 and Fig. 6 compare the predictions of the analytical model with the ADAPTIC [5,6] predictions for concrete material Models 1 to 4 from Table 1. Fig. 6a shows that the analytical model overestimates the buckle length as observed previously but the elastic critical buckling load is predicted reasonably accurately. Fig. $6 \mathrm{~b}$ shows the variation in the axial load eccentricity $(e)$ at the centre of the buckle with $P_{p}$, where $e$ is calculated from equation (16). Fig. $6 \mathrm{c}$ shows that all the analyses gave similar stresses in the extreme compressed fibre prior to concrete crushing at $f_{c}{ }^{\prime}=30 \mathrm{MPa}$ and that this point corresponded to member failure in Models 3 and 4. Fig. $6 \mathrm{~d}$ shows that the analytical model tends to underestimate the buckle amplitude as noted previously in the calibration of the model in Section 4.3.

\subsubsection{Case study 2: Medium length imperfection with $L_{g} / L_{p o}=0.4: f_{c}{ }^{\prime}=30 \mathrm{MPa}$}

Table 5 and Fig. 7 show that the response of this strut is broadly similar to that shown in Fig. 6 for $L_{g} / L_{p o}=0.1$ but the failure load calculated with Models 3 and 4 is closer to the elastic buckling load. Table 5 shows that the analytical model gives good 
predictions of the failure load calculated with Models 3 and 4 if the stress in the extreme compressive fibre calculated with equation (12) or (13) as appropriate is limited to the concrete strength of $f_{c}^{\prime}=30 \mathrm{MPa}$.

\subsubsection{Case study 3: Medium length imperfection with $L_{g} / L_{p o}=0.4: f_{c}{ }^{\prime}=80 \mathrm{MPa}$}

Table 6 and Fig. 8 compare the predictions of the analytical model with the ADAPTIC $[5,6]$ predictions for concrete material Models 1 to 4 from Table 1 . Fig. $8 \mathrm{c}$ shows that all the analyses predict the strut to fail in buckling before the extreme fibre stress reaches the concrete compressive strength of $80 \mathrm{MPa}$ with Model 4 giving the lowest failure load. The analytical model overestimates the buckling load as does the NLFEA with Model 1 since neither analysis accounts for the reduction in flexural rigidity due to cracking which reduces the critical buckling load.

\subsection{Influences of imperfection position and rotational restraint from retaining walls}

In classical Euler buckling theory, the buckling load of a column greatly depends on the rotational restraint at its ends. This is not always the case for blinding struts, where the influence of rotational restraint depends on i) the position of the ground imperfection within the width of the excavation, ii) the imperfection length $L_{g}$, iii) the critical buckling wavelength $L_{b}$ and iv) the excavation width $L_{\text {exc. }}$. Fig. 9 shows the results of a parametric study carried out with ADAPTIC $[6,7]$ to determine the effects of varying the imperfection length and rotational end restraint on the critical buckling load for symmetrically and asymmetrically positioned sinusoidal ground imperfection profiles. The asymmetric ground profiles were positioned with their left hand end in contact with the retaining wall as shown in Fig. 9a. The strut 
thickness was taken as $200 \mathrm{~mm}$, the imperfection amplitude as $100 \mathrm{~mm}$, the excavation width as $20 \mathrm{~m}$ and the concrete compressive strength as $30 \mathrm{MPa}$. The concrete was modelled with Model 4 from Table 1.

The buckle propagates asymmetrically in struts with asymmetrical ground imperfections as shown in Fig. 9a which is drawn for a pin ended strut. The buckle propagates in a similar way to that shown in Fig. 9a if the ends of the strut are rotationally fixed, but the restraining moments increase the buckling load to as much as double that for the pin ended strut. Fig. 9b shows the influence of imperfection length and rotational restraint on the predicted failure loads. The failure loads are independent of the rotational restraint provided by the retaining wall for the symmetrically positioned ground profiles since the critical buckle length is less than the excavation width. This will not always be the case for symmetrically positioned imperfections and is not the case for the asymmetrically positioned ground imperfection where the failure load is increased by rotational restraint at the ends of the strut.

\subsubsection{Modelling of asymmetric ground imperfections with the analytical model}

The analytical model needs to be modified before it can be applied to asymmetrically propagating buckles. Theoretical considerations suggest that the critical buckle length should be reduced by a factor of around 0.7 to account for the reduction in the critical elastic buckling load due to asymmetric buckling. Parametric studies show that i) the effect of reducing the effective length by a factor of 0.7 is to reduce the buckling load by around $30 \%$ and ii) the reduction in the concrete crushing load is similar. Table 7 compares the responses given by the analytical model and 
NLFEA with the linearly elastic (Model 1) and non-linear (Model 4) concrete models for $200 \mathrm{~mm}$ thick, $20 \mathrm{~m}$ long blinding struts with symmetrically and asymmetrically positioned imperfections of amplitude $50 \mathrm{~mm}$ and $100 \mathrm{~mm}$ respectively. The concrete compressive strength was taken as $30 \mathrm{MPa}$. The ground imperfections were assumed to be either sinusoidal or parabolic as noted in Table 7. The ends of the struts are assumed to have no rotational restraint. The analytical buckling loads for the asymmetrical profiles in Table 7 were calculated with equation (6) with $L_{p}=0.7 L_{b}$ (but not less than $L_{g}$ ) where $L_{b}$ is the critical buckle length for the corresponding symmetrically positioned imperfection. The analytical concrete crushing load for the asymmetrical imperfections was assumed to be 0.7 times that of the corresponding symmetric imperfection. In reality, the reduction in the crushing load due to asymmetric buckling is likely to be less than $30 \%$ since i) the ground imperfection is unlikely to be positioned with one end in contact with the retaining wall and ii) retaining walls provide some rotational restraint. Table 7 shows that the analytical model gives remarkably good predictions for the crushing and elastic buckling loads of the struts with symmetric and asymmetric imperfections. The crushing load of the pin ended struts is relatively insensitive to variations in the imperfection length for imperfection lengths between $5 \mathrm{~m}$ and $10 \mathrm{~m}$ as illustrated in Fig. $9 \mathrm{~b}$ for the $200 \mathrm{~mm}$ thick strut with $w_{\mathrm{g}}=100 \mathrm{~mm}$. The parabolic profile is not critical for the imperfection amplitudes considered in this example but can be critical for larger imperfection amplitudes or thicker slabs as shown in Fig. 20 of the companion paper [1]. 


\subsection{Observations from case studies}

The case studies show that the analytical model gives good predictions of the elastic buckling load for all the struts considered. The comparison with NLFEA is best for material Model 1 in which the concrete is modelled elastically with no tension cut-off. The NLFEA predictions with Model 1 diverge from those with Models 2 to 4 after cracking due to the consequent reduction in flexural rigidity which reduces the buckling load. The relatively small differences between the predictions of Models 3 and 4 are due to the use of a parabolic stress-strain curve for concrete in Model 4. Tables 4 to 6 show that the analytical model gives reasonable estimates of the load at specified loading eccentricities at the centre of the buckle for $e=M / P \leq h / 5$. Thereafter, the analytical model progressively underestimates the loading eccentricity, and hence the extreme fibre concrete compressive stress, as a result of neglecting the reduction in stiffness due to cracking which reduces the buckling load.

\section{Design chart}

The simplified model for the case of sinusoidal imperfections developed in Section 3.2, with the adjustment given by equation (16) for the effect of the overestimated buckle length, can be conveniently presented in the form of a design chart applicable for $L_{g}<L_{p o}$, as depicted in Fig. 10. The solid lines show the variation in the propagating buckle wavelength with load for specific imperfection lengths. The dashed lines are contours of $e / w_{g}$ and can be used to determine the loading eccentricity at any point along the solid lines. The load and wavelength are normalised by the respective empathetic values $P_{c o}$ and $L_{p o}$, where $P_{c o}$ is given by: 
$P_{c o}=\frac{4 \pi^{2} E I}{L_{p o}^{2}}$

where $L_{p o}$ is given by equation (1). The design chart gives useful insights into the key parameters which govern the structural response of the blinding strut. For example, the chart shows that a lower limit needs to be placed on the imperfection length $L_{g}$ to achieve a significant resistance at low eccentricity $e$. The chart may also be used to set physical constraints on $L_{b}$ (from excavation boundaries) to establish the range of resistance corresponding to a range of initial imperfection lengths.

\section{Design example}

This section illustrates the design of a blinding strut in a typical cut-and-cover excavation using the design chart, where the results are compared with NLFEA. The excavation considered in this example is $20 \mathrm{~m}$ wide and $10 \mathrm{~m}$ deep. A cantilevered retaining wall is used with an embedded length of $10 \mathrm{~m}$. The soil type is assumed to be London Clay overlain with $2.5 \mathrm{~m}$ of Terrace Gravel. The pore water pressure is taken at the interface of the two soil types. Geotechnical analysis [4] with ICFEP [11] shows that the maximum strut force is around $1200 \mathrm{kN} / \mathrm{m}$. The design ultimate load was calculated with the load factors given in BS5400 [8,9] to be $2000 \mathrm{kN} / \mathrm{m}$. The ground imperfection is uncertain in reality but needs to be assumed for design. For purposes of illustration, the imperfection is assumed to be either i) parabolic with amplitude $w_{g}=100 \mathrm{~mm}$ and length $L_{e x c}=20 \mathrm{~m}$ or ii) a symmetrically positioned sinusoid with amplitude $100 \mathrm{~mm}$ and length $L_{g}=5 \mathrm{~m}$. The strut is assumed to be cast on the ground imperfection, although in practice the imperfection would arise due to the 
combined effects of heave and initial lack of flatness. The characteristic concrete cylinder strength is taken as $30 \mathrm{MPa}$.

The blinding strut fails at the least of the critical buckling load or the load at which the extreme fibre stress equals the characteristic concrete cylinder strength. It is suggested that the design strength of the blinding strut is obtained by dividing the failure load calculated with the characteristic concrete strength by the material factor of safety of $\gamma_{d} / \alpha=1.5 / 0.85=1.76$ used for concrete in compression in the UK Annex to Eurocode 2 [9]. This approach gives a consistent factor of safety for concrete crushing and elastic buckling and is typically more conservative than calculating the failure load in terms of the design concrete strength $f_{c d}=\alpha f_{c k} / \gamma_{c}$. It follows that the required blinding strut axial resistance is $2000 \times 1.76=3530 \mathrm{kN} / \mathrm{m}$.

\subsection{Analytical solution}

The failure load should be taken as the least of the failure loads for the assumed parabolic and sinusoidal ground imperfections. The strut thickness is taken as $300 \mathrm{~mm}$ here but in general needs to be determined by a process of iteration. The failure load for the parabolic imperfection is calculated with equation (2) to be $3600 \mathrm{kN} / \mathrm{m}$ which is greater than the required resistance of $3530 \mathrm{kN} / \mathrm{m}$. Fig. 11 illustrates the solution of the analytical method with the design chart assuming a sinusoidal ground imperfection. The first step is to calculate the empathetic buckle length $L_{p o}$, which is obtained from equation (1) as $24.89 \mathrm{~m}$ for the $100 \mathrm{~mm}$ high imperfection considered. It also follows that $L_{g} / L_{p o}=0.20$ for the $5 \mathrm{~m}$ long imperfection considered. The following critical loads can be read from Fig. 11: 
Buckling occurs when $L_{b} / L_{p o}$ equals the maximum possible value of 0.80 which is governed by the excavation width of $20 \mathrm{~m}$. At this point, $P_{b} / P_{c o}=1.44$ which corresponds to $P_{b}=6603 \mathrm{kN} / \mathrm{m}$.

Cracking can be monitored in terms of the eccentricity $e$. The increase in eccentricity as the strut cracks can be traced by calculating the value of $e / h$ corresponding to the intersection of the dotted lines representing $e / w_{g}$ with the solid line corresponding to $L_{g} / L_{p o}=0.20$. The value of $e / w_{g}$ corresponding to $e=h / 6$, representing the onset of cracking, is circled in Fig. 11.

Crushing occurs when the stress in the bottom fibre at the centre of the buckle reaches the concrete compressive strength. The stress in the bottom fibre can be calculated with equation (12) or (13) as appropriate with $P$ and $e$ taken from the design chart. Alternatively, e can be calculated with equation (16). In this case, crushing occurs when $P_{\text {crush }} / P_{c o}=0.77$ and $L_{p} / L_{p o}=0.54$, resulting in $P_{\text {crush }}=3532$ $\mathrm{kN} / \mathrm{m}$ which is satisfactory.

The required strut thickness is dependent on the assumed ground imperfection, which should be related to the likely ground heave and construction tolerances. For example, the failure load corresponding to an asymmetrically positioned sinusoidal imperfection with one end in contact with the retaining wall is estimated to be $0.7 \times 3523=2473 \mathrm{kN} / \mathrm{m}$ which is less than the required resistance of $3530 \mathrm{kN} / \mathrm{m}$. The failure load was also calculated for the symmetrically and asymmetrically positioned imperfections with NLFEA using material Model 4 . The failure loads were found to be $3913 \mathrm{kN} / \mathrm{m}$ and $2925 \mathrm{kN} / \mathrm{m}$, which compare reasonably with the failure loads of $3530 \mathrm{kN} / \mathrm{m}$ and $2473 \mathrm{kN} / \mathrm{m}$ given by the analytical method. Fig. 12 shows the variation in the strut resistance with 
imperfection amplitude, according to the analytical model, for parabolic and symmetrically positioned sinusoidal imperfections of varying lengths. The figure clearly demonstrates the sensitivity of the strut resistance to the imperfection amplitude.

\section{Conclusions}

This paper presents an analytical model for the design of blinding struts, which builds on the clamped column analogy of Croll [2,3], and deals with the specific features of upheaval buckling for struts having a finite length. The model is incorporated into a design chart which provides a convenient way of evaluating and visualising the effect of variations in the imperfection amplitude and length. The design chart can be used to trace the increase in buckle length with axial load and to consider the effect of cracking which is most critical for short imperfection lengths. The analytical model gives similar predictions of the critical buckling load to NLFEA if the concrete is assumed to be elastic. The analytical model also gives reasonable predictions of the failure load given by NLFEA with concrete non-linearity if failure is assumed to occur when the extreme fibre stress at the centre of the buckle, calculated assuming zero tension in the concrete, reaches the design concrete strength.

The minimum permissible thickness of a blinding strut is influenced by many factors including the amplitude and position of its geometrical imperfection, construction tolerances and uncertainties in material properties and loading. The choice of the design imperfection due to lack of flatness is dependent on construction tolerances. There is clearly a trade off between flatness and strut 
thickness which needs to be considered on a case by case basis. It is the engineer's responsibility to determine the amplitude and position of the geometrical imperfection to be considered in design. Having done so, the engineer can use the analytical model to determine the minimum thickness of a blinding strut, with regard to its axial resistance, for either symmetrical or asymmetrical geometrical imperfections. The analysis should take due account of construction tolerances and uncertainties in axial loading and material properties. The resulting strut thickness may need to be increased to resist loadings from construction traffic or for other practical considerations.

The effects of ground heave and creep should also be considered in the design of blinding struts both of which will be covered in subsequent publications. It has been shown [4] through a combination of structural testing on $1 / 4$ scale models and NLFEA that creep is unlikely to significantly reduce the strength of blinding struts if $P_{\text {perm }} / P_{u}<0.5$ where $P_{\text {perm }}$ is the sustained load and $P_{u}$ is the short term failure load. This is likely to be the case in practice when load and material partial factors are taken into account. Otherwise, if this is not the case, the effects of creep should be rigorously accounted for.

\section{Acknowledgements}

The authors would like to thank Alan Powderham for bringing blinding struts to their attention and for his continued support throughout the project. We also wish to acknowledge the financial support of the Engineering and Physical Sciences Research Council (EPSRC) under grant EP/D505488/1. 


\section{Notation}

$d_{\text {exc }}^{-}, d_{\text {exc }}^{+}$Distance from centreline of imperfection to edges of excavation

e Eccentricity of the resultant line of thrust with respect to slab centreline

h $\quad$ Blinding strut thickness

$q \quad$ Self-weight per unit length

E Elastic modulus

I Second moment of area

$L_{p o} \quad$ Empathetic wavelength at wich the amplitudes of the foundation and loading imperfections are equal.

$L_{\text {exc }} \quad$ Width of excavation

$L_{g} \quad$ Wavelength of ground imperfection

$L_{b} \quad$ Critical buckle wavelength at critical buckling load $P_{b}$

$P_{b} \quad$ Critical buckling load

$P_{c o} \quad$ Empathetic buckling load

$P_{L} \quad$ Axial load at first lift-off

$P_{p} \quad$ Buckle propagation load

w' Maximum buckle amplitude

$w_{L} \quad$ Amplitude of loading imperfection

$w_{g} \quad$ Amplitude of geometric imperfection

$w_{g}{ }^{\prime} \quad$ Amplitude of equivalent geometric imperfection used in the analytical model

$\sigma \quad$ Stress

$\omega \quad$ Ratio of amplitudes of the equivalent and real geometric imperfections 


\section{References}

1 Abela, J. M., Vollum, R. L., Izzuddin, B. A. \& Potts, D. M. (2010a) Blinding struts: Part 1, (Companion paper).

2 Croll, J. G. A. (1997) A simplified model of the upheaval buckling of subsea pipelines. Thin Walled Structures, 29, 59-78

3 Croll, J. G. A. (1998) A simplified analysis of imperfect thermally buckled subsea pipelines. International J of Offshore and Polar Engineering, 8 (4), 283-291

4 Abela, J. M. (2009) Blinding struts in cut-and-cover excavations. Thesis submitted for the degree of Doctor of Philosophy in the University of London, Department of Civil Engineering, Imperial College, London

5 Izzuddin, B. A. (2007) Rotational spring analogy for buckling analysis. Journal of Structural Engineering, ASCE, Vol. 133, pp. 739-751.

6 Izzuddin, B. A. (1991) Nonlinear dynamic analysis of framed structures. Thesis submitted for the degree of Doctor of Philosophy in the University of London, Department of Civil Engineering, Imperial College, London

7 Izzuddin, B. A. (2009) ADAPTIC Manual Version 1.3b, Imperial College, London http://hdl.handle.net/10044/1/4228

8 BS 5400-2:2006 Steel, concrete and composite bridges. Specification for loads. British Standards Institution

9 BS 5400-4:1990 Steel, concrete and composite bridges. Code of practice for design of concrete bridges. British Standards Institution

10 BSI (British Standards Institution) (2005) UK national annex to Eurocode 2: design of concrete structures. Part 1: General rules and rules for buildings. BSI, London. 
11 Potts, D. M. \& Zdravković, L. (2001) Finite Element Analysis in Geotechnical Engineering: Volume II-Application, Telford Publishing, London 


\section{APPENDIX: Derivation of design equations}

The design equations can be derived as follows:

Firstly, it is convenient to define the following terms in which the "bar" denotes dependence on $\mathrm{L}$.

$\bar{w}_{L}=w_{L} \frac{L^{4}}{L_{p}^{4}}=\beta w_{g}^{\prime} \frac{L^{4}}{L_{p}^{4}}$

$\bar{P}_{c}=P_{c} \frac{L_{p}^{2}}{L^{2}}$

where $L_{p}$ is the buckle propagation length and $P_{c}=\frac{4 \pi^{2} E I}{L_{p}^{2}}$.

The buckle amplitude of the equivalent imperfection relative to the lift off points is given by:

$$
w^{\prime}=\frac{w_{g}^{\prime}-\bar{w}_{L}}{1-\frac{\bar{P}_{p}}{\bar{P}_{c}}}=\frac{w_{g}^{\prime}\left(1-\beta \frac{L^{4}}{L_{p}^{4}}\right)}{1-\frac{\bar{P}_{p}}{P_{c}} \frac{L^{2}}{L_{p}^{2}}}
$$

Rearranging equation (A.3) gives the buckle propagation load:

$$
\bar{P}_{p}=\left[1-\frac{w_{g}^{\prime}}{w^{\prime}}\left(1-\beta \frac{L^{4}}{L_{p}^{4}}\right)\right] P_{c} \frac{L_{p}^{2}}{L^{2}}
$$

The minimum buckle propagation load is found by differentiating Equation (A.4) with respect to $\mathrm{L}$.

$$
\left.\frac{d \bar{P}_{p}}{d L}\right|_{L=L_{p}}=0 \Rightarrow w^{\prime}=(1+\beta) w_{g}^{\prime}
$$

and the buckle propagation load is given by:

$$
P_{p}=\bar{P}_{p\left(L=L_{p}\right)}=\frac{2 \beta}{1+\beta} P_{c}
$$




\section{List of Tables}

Table 1: Concrete material properties used in the ADAPTIC analysis

Table 2: Case study 1: Comparative results from the analytical model and ADAPTIC Table 3 Geometrical properties of the slabs used in Case studies 2 and 3.

Table 4: Case study 2: $L_{g} / L_{p o}=0.1, f_{c k}=30 \mathrm{MPa}$, Comparative results from the analytical model and ADAPTIC

Table 5: Case study 2: $\mathrm{Lg}_{\mathrm{g}} / \mathrm{L}_{\mathrm{po}}=0.4, \mathrm{f}_{\mathrm{ck}}=30 \mathrm{MPa}$, Comparative results from the analytical model and ADAPTIC

Table 6: Case study 2: $\mathrm{Lg}_{\mathrm{g}} / \mathrm{L}_{\mathrm{po}}=0.4, \mathrm{f}_{\mathrm{ck}}=80 \mathrm{MPa}$, Comparative results from the analytical model and ADAPTIC

Table 7: Comparison of failure loads for symmetric and asymmetric imperfections 


\begin{tabular}{|c|c|c|c|c|c|c|c|c|c|}
\hline \multicolumn{2}{|c|}{$\begin{array}{c}\text { Material Properties } \\
\text { (Izzuddin, } 1991 \text { \& Izzuddin, 2009) }\end{array}$} & \multicolumn{2}{|c|}{$\begin{array}{c}\text { stl1 } \\
\text { Model } 1\end{array}$} & \multicolumn{2}{|c|}{$\begin{array}{c}\text { con1 } \\
\text { Model } 2\end{array}$} & \multicolumn{2}{|c|}{$\begin{array}{c}\text { con1 } \\
\text { Model } 3\end{array}$} & \multicolumn{2}{|c|}{$\begin{array}{c}\operatorname{con1}^{\S} \\
\text { Model } 4\end{array}$} \\
\hline ADAPTIC properties & $\begin{array}{l}\text { Concrete } \\
\text { strength } \mathrm{f}_{\mathrm{c}}^{\prime}\end{array}$ & - & - & - & - & 30 & 80 & 30 & 80 \\
\hline Compressive strength & $f_{c 1}(\mathrm{MPa})$ & - & - & - & - & 30 & 80 & 30 & 80 \\
\hline Tensile strength & $f_{t}(M P a)$ & - & - & 0 & 0 & 3.0 & & 3.0 & \\
\hline $\begin{array}{l}\text { Residual compressive } \\
\text { strength }\end{array}$ & $f_{c 2}(M P a)$ & - & - & - & - & 6.0 & 16.0 & 6.0 & 16.0 \\
\hline $\begin{array}{l}\text { Initial tangent elastic } \\
\text { modulus }\end{array}$ & $E(G P a)$ & 32 & 39.7 & 32 & 39.7 & 32 & 39.7 & 32 & 39.7 \\
\hline Secant modulus at $\mathrm{f}_{\mathrm{c}}{ }^{\prime}$ & $E_{c 1}(G P a)$ & 32 & 39.7 & 32 & 39.7 & 32 & 39.7 & 16 & 19.9 \\
\hline Density & $\mathrm{kN} / \mathrm{m}^{3}$ & & & & & 24 & & & \\
\hline
\end{tabular}

$\S$ The stress strain diagram used in Model 4 is defined in Fig. 5 of the companion paper [1]

Table 1: Concrete material properties used in the ADAPTIC analysis

\begin{tabular}{l|c|c|c|c}
\hline & \multicolumn{2}{|c|}{ ANALYTICAL SOLUTION } & \multicolumn{2}{c}{ NUMERICAL SOLUTION } \\
\hline Properties & No Tension Load & $\begin{array}{c}\text { Critical buckling } \\
\text { load }\end{array}$ & No Tension Load & $\begin{array}{c}\text { Critical buckling } \\
\text { load }\end{array}$ \\
\hline$L_{b}(\mathrm{~mm})$ & 7350 & 20550 & 5600 & 21130 \\
\hline$P_{b}(\mathrm{kN} / \mathrm{m})$ & 1435 & 12030 & 720 & 11720 \\
\hline$L_{b} / L_{p o}$ & 0.28 & 0.78 & 0.21 & 0.80 \\
\hline$P_{b} / P_{c o}$ & 0.23 & 1.95 & 0.12 & 1.90 \\
\hline$w^{\prime}(\mathrm{mm})$ & 0.60 & 36.9 & 0.24 & 45.5 \\
\hline
\end{tabular}

Table 2: Comparative results from the analytical model and ADAPTIC

\begin{tabular}{l|c|c|c}
\hline & Case 1 & Case 2 & Case 3 \\
\hline$L_{g} / L_{p o}$ & $\mathbf{0 . 1}$ & $\mathbf{0 . 4}$ & $\mathbf{0 . 4 2}$ \\
\hline$L_{g}(\mathrm{~mm})$ & 2250 & 9480 & 9480 \\
\hline$b(\mathrm{~mm})$ & 1000 & 1000 & 1000 \\
\hline$h(\mathrm{~mm})$ & 335 & 300 & 300 \\
\hline$W_{g}(\mathrm{~mm})$ & 70 & 91 & 91 \\
\hline$L_{p o}(\mathrm{~mm})$ & 24060 & 24315 & 25660 \\
\hline
\end{tabular}

Table 3: Geometrical properties of the slabs used in Case studies 1 to 3.

\begin{tabular}{l|c|c|c|c|c}
\hline Load $(\boldsymbol{k N})$ & \multicolumn{1}{c}{ Analytical } & \multicolumn{1}{c}{ Model 1 } & Model 2 & Model 3 & Model 4 \\
\hline Load at $e=h / 6$ & 4620 & 3880 & 3800 & 3920 & 3720 \\
\hline Crushing $\left(\sigma_{c}=30 \mathrm{MPa}\right)$ & 4855 & 4940 & 5090 & 5040 & 5800 \\
\hline Load at $e=h / 5$ & 12650 & 11400 & 11220 & - & - \\
\hline Load at $e=h / 4$ & 13200 & - & 12580 & - & - \\
\hline Buckling & 13685 & 13350 & 13140 & 6920 & 5895 \\
\hline
\end{tabular}

Table 4: Case study 1: $L_{g} / L_{p o}=0.1, f_{c}{ }^{\prime}=30 \mathrm{MPa}$, Comparative results from the analytical model (with $\mathrm{c}=0.8$ ) and ADAPTIC 


\begin{tabular}{l|c|c|c|c|c}
\hline Load $(\mathbf{k N})$ & Analytical & Model 1 & Model 2 & Model 3 & Model 4 \\
\hline Load at $e=h / 6$ & 2520 & 3265 & 3265 & 3200 & 3200 \\
\hline Load at $e=h / 5$ & 3930 & 4160 & 4135 & 4145 & 3720 \\
\hline Crushing $\left(\sigma_{c}=30 \mathrm{MPa}\right)$ & 3965 & 4080 & 4095 & 4120 & 4070 \\
\hline Load at $e=h / 4$ & 5110 & 5440 & 4920 & - & 4070 \\
\hline Buckling & 5635 & 5520 & 5040 & 4370 & 4070 \\
\hline
\end{tabular}

Table 5: Case study 2: $L_{g} / L_{p o}=0.4, f_{c}{ }^{\prime}=30 \mathrm{MPa}$, Comparative results from the analytical model (with $\mathrm{c}=0.8$ ) and ADAPTIC

\begin{tabular}{l|c|c|c|c|c}
\hline Load $(\mathbf{k N})$ & Analytical & Model 1 & Model 2 & Model 3 & Model 4 \\
\hline Load at $e=h / 6$ & 2760 & 3520 & 3520 & 3520 & 3440 \\
\hline Load $\left(\sigma_{c}=30 \mathrm{MPa}\right)$ & 4115 & 4240 & 4240 & 4240 & 4250 \\
\hline Load at $e=h / 5$ & 4340 & 4480 & 4560 & 4560 & 4400 \\
\hline Load at $e=h / 4$ & 5695 & 5680 & 5520 & 5585 & 5210 \\
\hline Crushing $\left(\sigma_{c}=80 \mathrm{MPa}\right)$ & 6370 & - & 4770 & - & - \\
\hline Load at $e=h / 3$ & 6390 & 6255 & 5315 & 5420 & 4900 \\
\hline Buckling & 6395 & 6260 & 5680 & 5765 & 5310 \\
\hline
\end{tabular}

Table 6: Case study 3: $L_{g} / L_{p o}=0.4, f_{c}{ }^{\prime}=80 \mathrm{MPa}$, Comparative results from the analytical model (with $\mathrm{c}=0.8$ ) and ADAPTIC

\begin{tabular}{|c|c|c|c|c|c|c|c|c|}
\hline Load (kN) & \multicolumn{8}{|c|}{ Failure loads (kN/m) } \\
\hline Imperfection $\mathrm{w}_{\mathrm{g}}=50 \mathrm{~mm}$ & \multicolumn{3}{|c|}{ Symmetric (sine) } & \multicolumn{3}{|c|}{ Asymmetric (sine) } & \multirow{2}{*}{$\begin{array}{c}\text { Sine } \\
20\end{array}$} & \multirow{2}{*}{\begin{tabular}{|c} 
Parabolic \\
20
\end{tabular}} \\
\hline $\begin{array}{ll}L_{g} & (m)\end{array}$ & 5 & 10 & 15 & 5 & 10 & 15 & & \\
\hline ADAPTIC Model $1 \sigma_{c}=30 \mathrm{MPa}$ & 2775 & 2855 & 2810 & 2500 & 2265 & $2020^{*}$ & $2835^{*}$ & - \\
\hline Analytical $\sigma_{c}=30 \mathrm{MPa}$ & 2705 & 2740 & 2740 & $1890^{+}$ & $1920^{\dagger}$ & $1920^{+}$ & 2955 & 6000 \\
\hline ADAPTIC Model 1 Buckling & 3660 & 2960 & 2810 & 3100 & 2270 & 2640 & 3095 & 4575 \\
\hline ADAPTIC Model 4 Buckling & 2800 & 2515 & 2500 & 2190 & 2010 & 2455 & 2845 & 4577 \\
\hline Analytical Buckling & 3735 & 2990 & 2830 & 2610 & 2380 & 2790 & 2965 & 4800 \\
\hline Load (kN) & \multicolumn{8}{|c|}{ Failure loads (kN/m) } \\
\hline Imperfection $\mathrm{w}_{\mathrm{g}}=100 \mathrm{~mm}$ & \multicolumn{3}{|c|}{ Symmetric (sine) } & \multicolumn{3}{|c|}{ Asymmetric (sine) } & Sine & Parabolic \\
\hline $\begin{array}{ll}L_{g} & (m)\end{array}$ & 5 & 10 & 15 & 5 & 10 & 15 & 20 & 20 \\
\hline ADAPTIC Model $1 \sigma_{c}=30 \mathrm{MPa}$ & 2095 & 1940 & 1975 & 1580 & 1605 & $1560^{*}$ & - & - \\
\hline Analytical $\sigma_{c}=30 \mathrm{MPa}$ & 1470 & 1625 & 1715 & $1030^{+}$ & $1140^{\dagger}$ & 1415 & 2005 & 6000 \\
\hline ADAPTIC Model 1 Buckling & 2750 & 2190 & 2000 & 2420 & 1695 & 1600 & 2380 & 2370 \\
\hline ADAPTIC Model 4 Buckling & 1660 & 1590 & 1645 & 1145 & 1220 & 1470 & 1790 & 2370 \\
\hline Analytical Buckling & 2815 & 2210 & 2010 & 1980 & 1660 & 1715 & 2040 & 2400 \\
\hline
\end{tabular}

Notes: † Assumed to be 0.7 times the crushing load for the symmetric imperfection,

* buckling is predicted to occur before crushing.

Table 7: Comparison of failure loads for symmetric and asymmetric imperfections for $200 \mathrm{~mm}$ thick strut. 


\section{List of figures}

Figure 1: Displaced shape of retaining wall

Figure 2: Transformation of actual sinusoidal geometric imperfection into equivalent sinusoidal imperfection; (a) actual imperfection of length $L_{g}$ and (b) equivalent imperfection of length $L_{p}$.

Figure 3: Influence of loading eccentricity on stress distribution in cracked section.

Figure 4: Comparison between analytical model and NLFEA for (a) buckle amplitude, (b) bottom fibre stress c) top fibre stress, d) top fibre stress near "no tension" load and e) buckle wavelength.

Figure 5: Comparison between modified analytical model and NLFEA for a) top fibre stress, b) top fibre stress near "no tension" load.

Figure 6: Case study 1: $L_{g} / L_{p o}=0.1, f_{c k}=30 \mathrm{MPa}$ : Comparison between modified analytical model and NLFEA for a) buckle length, b) eccentricity, c) bottom fibre stress, d) buckle amplitude.

Figure 7: Case Study 2: $\mathrm{L}_{\mathrm{g}} / \mathrm{L}_{\mathrm{po}}=0.4, \mathrm{f}_{\mathrm{ck}}=30 \mathrm{MPa}$ : Comparison between modified analytical model and NLFEA for a) buckle length, b) eccentricity, c) bottom fibre stress, d) buckle amplitude

Figure 8: Case study 3: $L_{g} / L_{p o}=0.4, f_{c k}=80 \mathrm{MPa}$ : Comparison between modified analytical model and NLFEA for a) buckle length, b) eccentricity, c) bottom fibre stress, d) buckle amplitude

Figure 9: Buckling of struts with symmetric and asymmetric imperfection profiles (strut thickness $=200 \mathrm{~mm}, \mathrm{w}_{\mathrm{g}}=100 \mathrm{~mm}, \mathrm{~L}_{\mathrm{exc}}=20 \mathrm{~m}$ and $\mathrm{f}_{\mathrm{ck}}=30 \mathrm{MPa}$ ); (a) Propagation of the asymmetric $5 \mathrm{~m}$ profile for pin ended strut (buckling load reached at vertical displacement of $32 \mathrm{~mm}$ ); (b) Effect of rotational restraint on the critical buckling load for symmetric and asymmetric imperfection profiles of varying length Figure 10: Design chart

Figure 11: Illustration of use of design chart

Figure 12: Influence of imperfection amplitude on a) buckling load and b) concrete crushing load ( $f_{c k}=30 \mathrm{MPa}$ ) for $300 \mathrm{~mm}$ thick strut with i) symmetrically positioned sinusoidal imperfections of length $5 \mathrm{~m}$ and $10 \mathrm{~m}$ and ii) parabolic imperfection. 


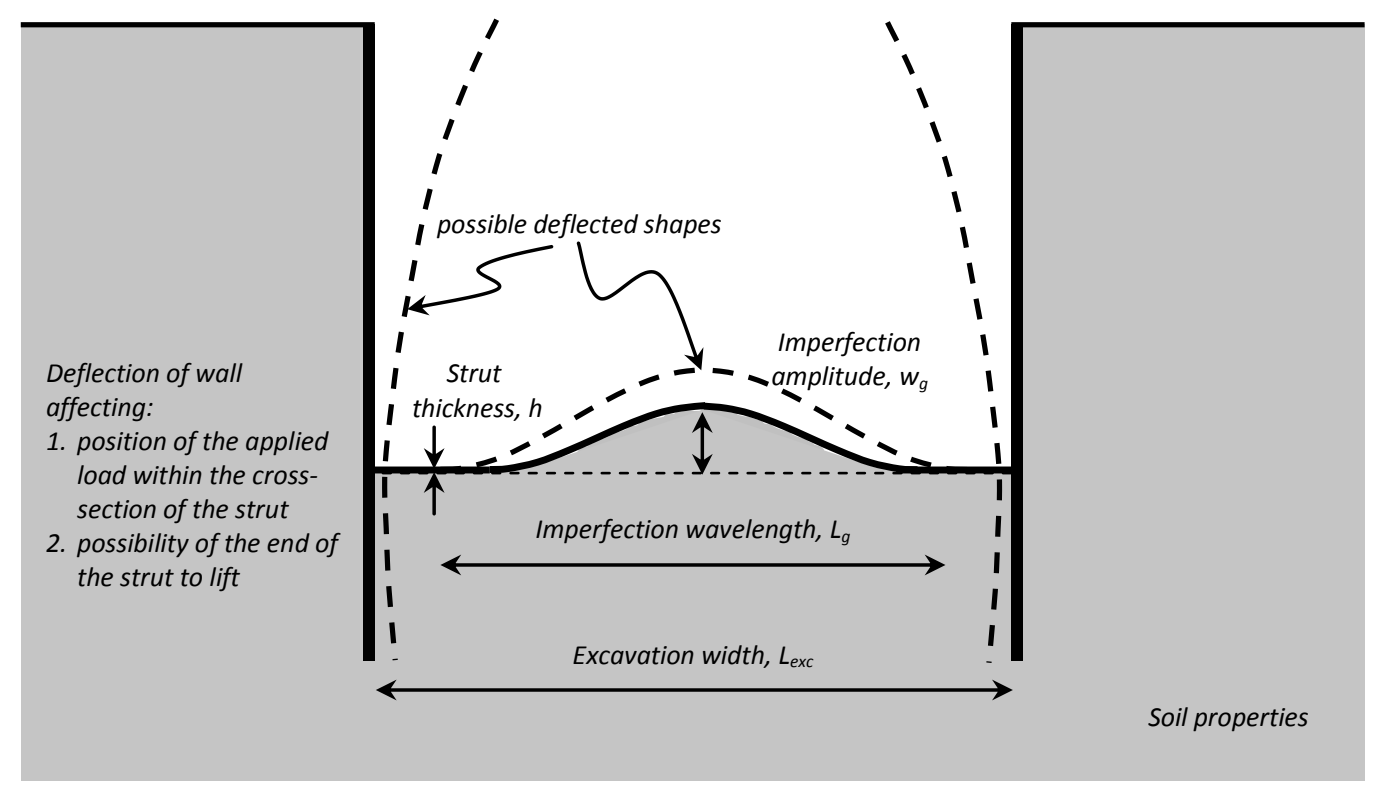

Figure 1: Displaced shape of retaining wall 


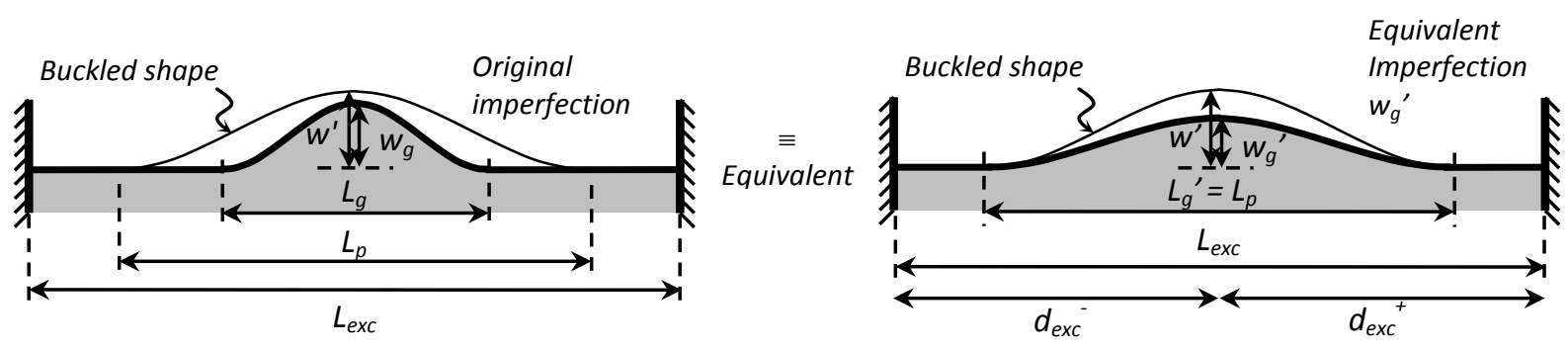

(a)

(b)

Figure 2: Transformation of actual sinusoidal geometric imperfection into equivalent sinusoidal imperfection; (a) actual imperfection of length $L_{g}$ and (b) equivalent imperfection of length $L_{p}$. 


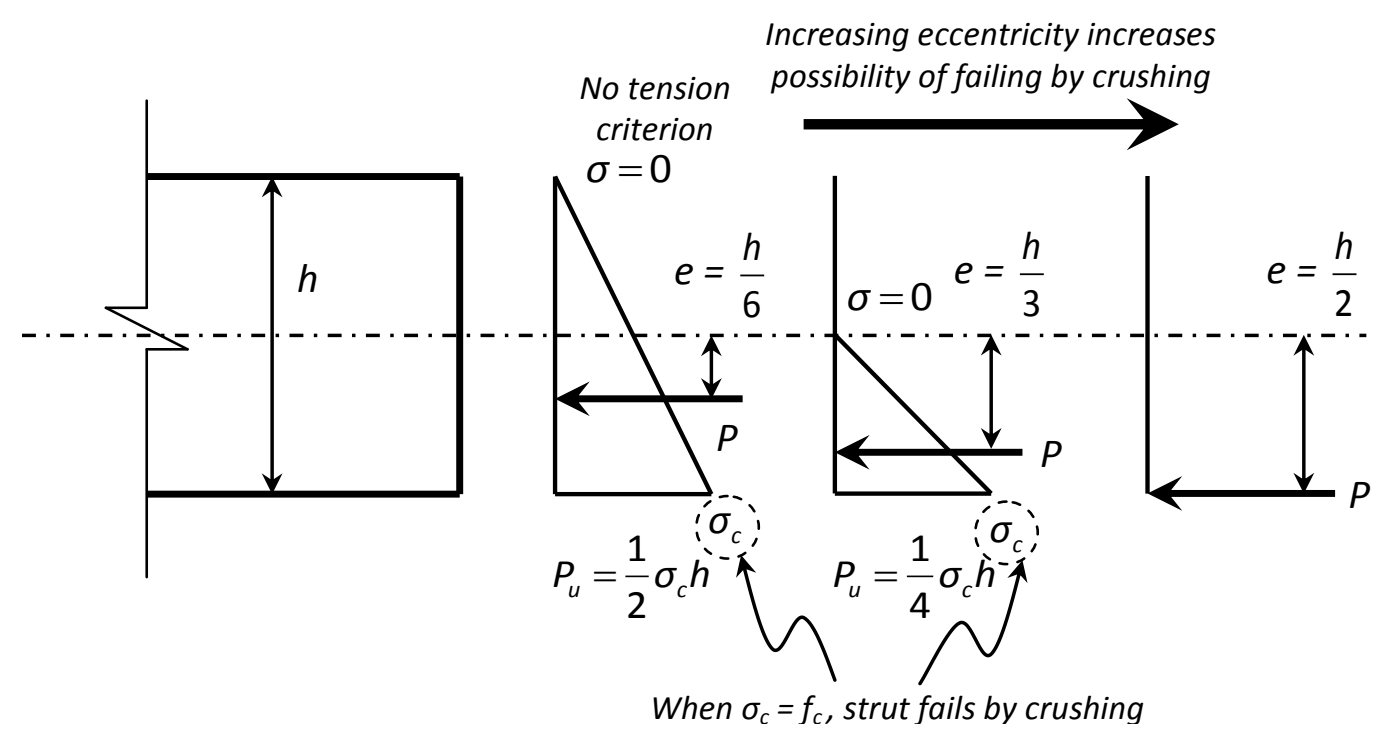

Figure 3: Influence of loading eccentricity on stress distribution in cracked section. 


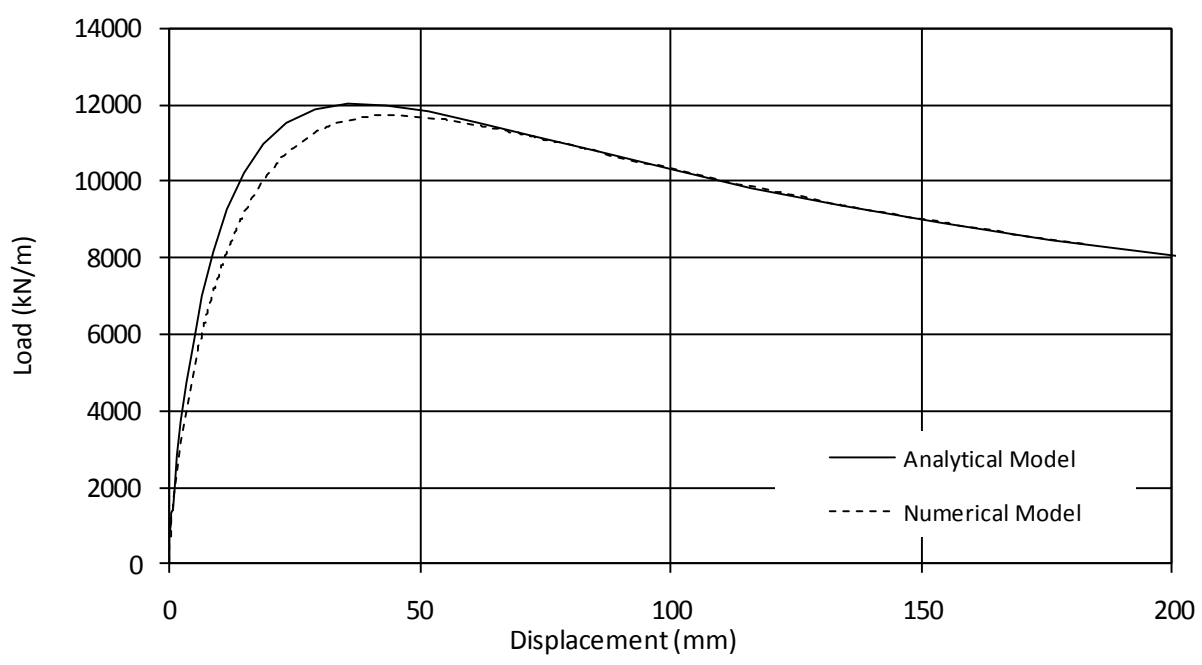

(a) Load versus buckle amplitude

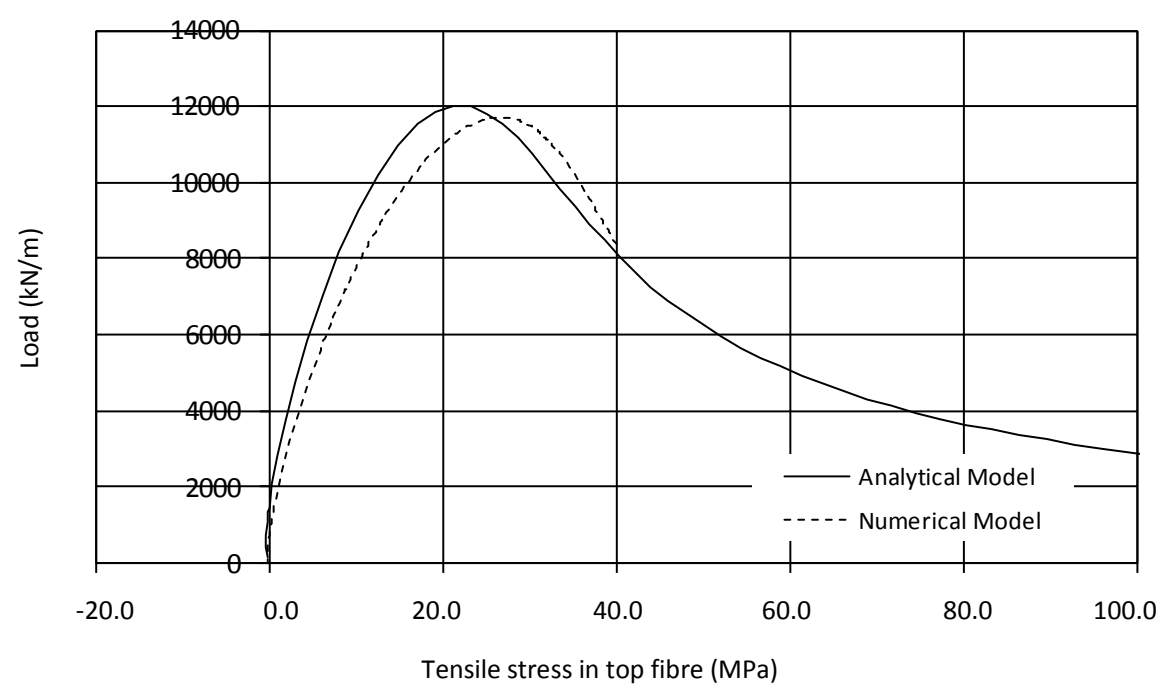

(b) Load versus top fibre stress

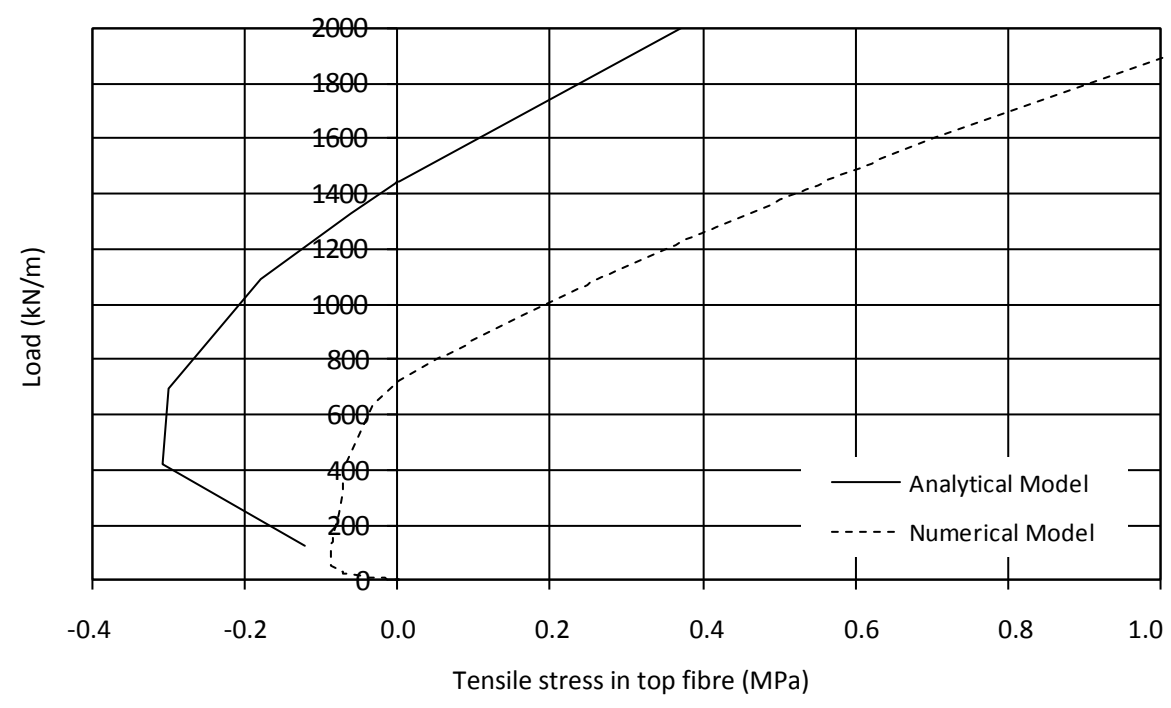

(c) Load versus top fibre stress near "no tension" load 


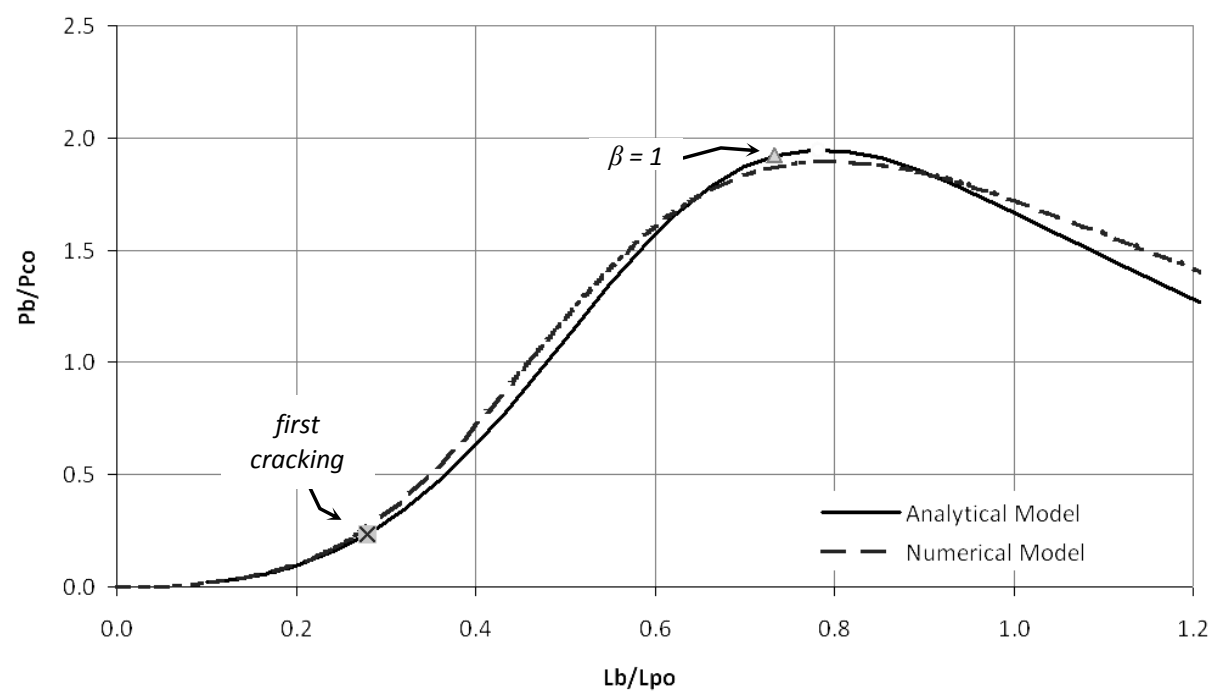

(d) Load versus buckle wavelength

Figure 4: Comparison between analytical model and NLFEA 


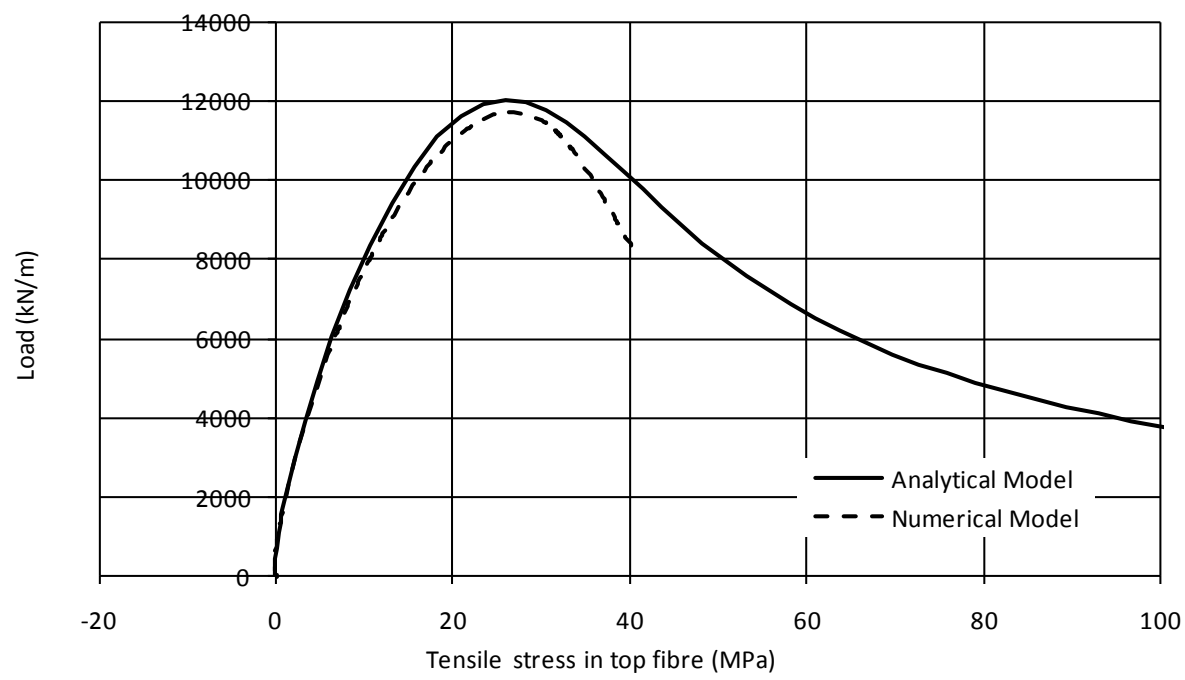

(a) Load versus top fibre stress

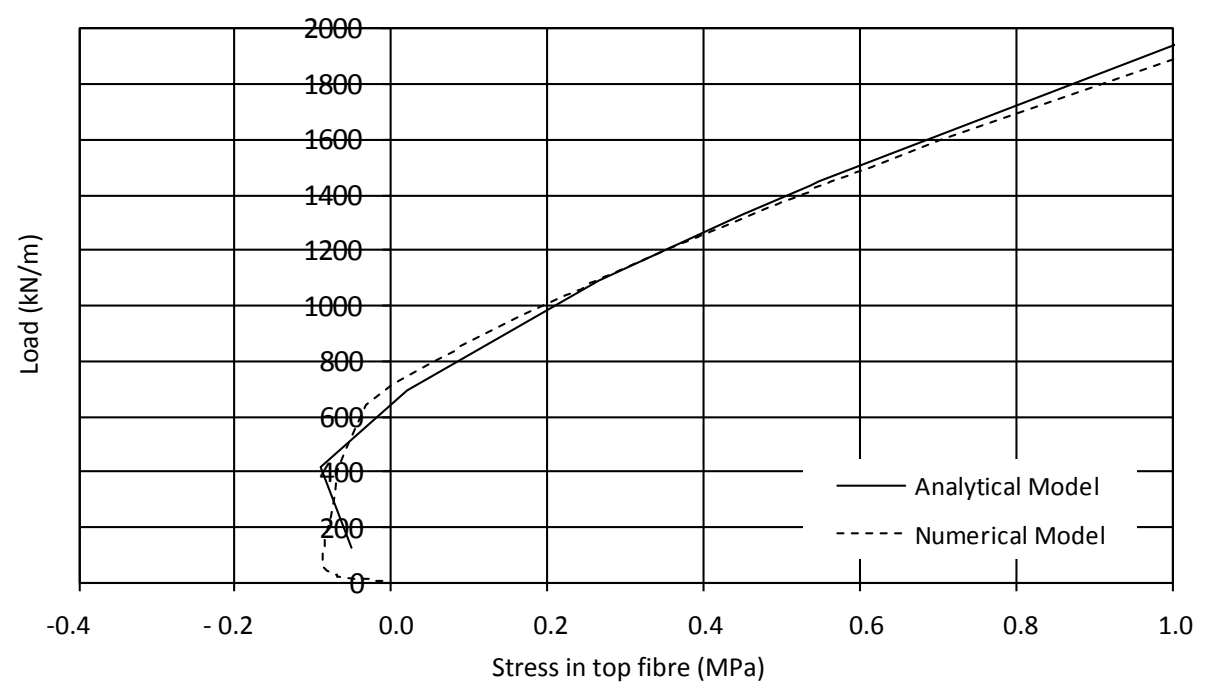

(b) Load versus top fibre stress near "no tension" load

Figure 5: Comparison between modified analytical model and NLFEA 


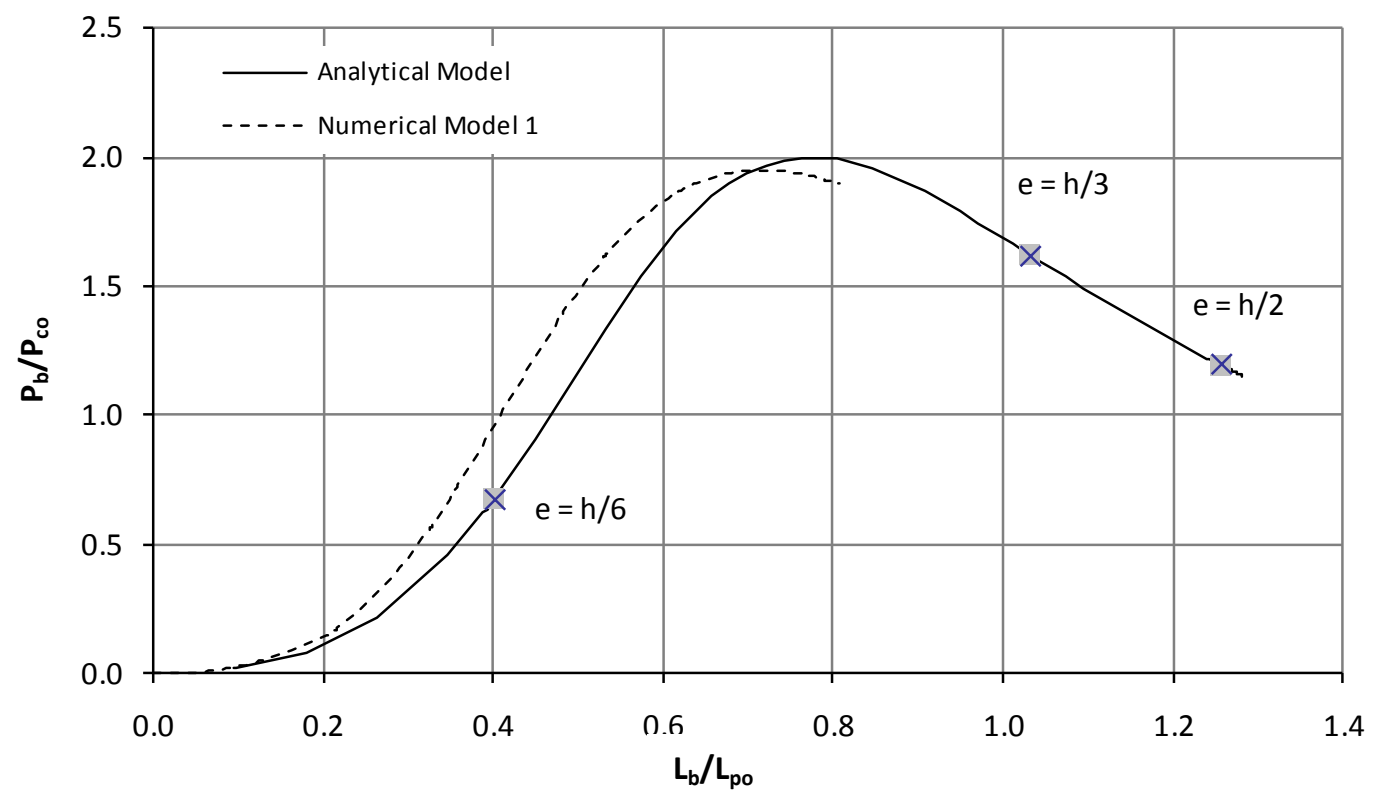

(a) Load versus top fibre stress

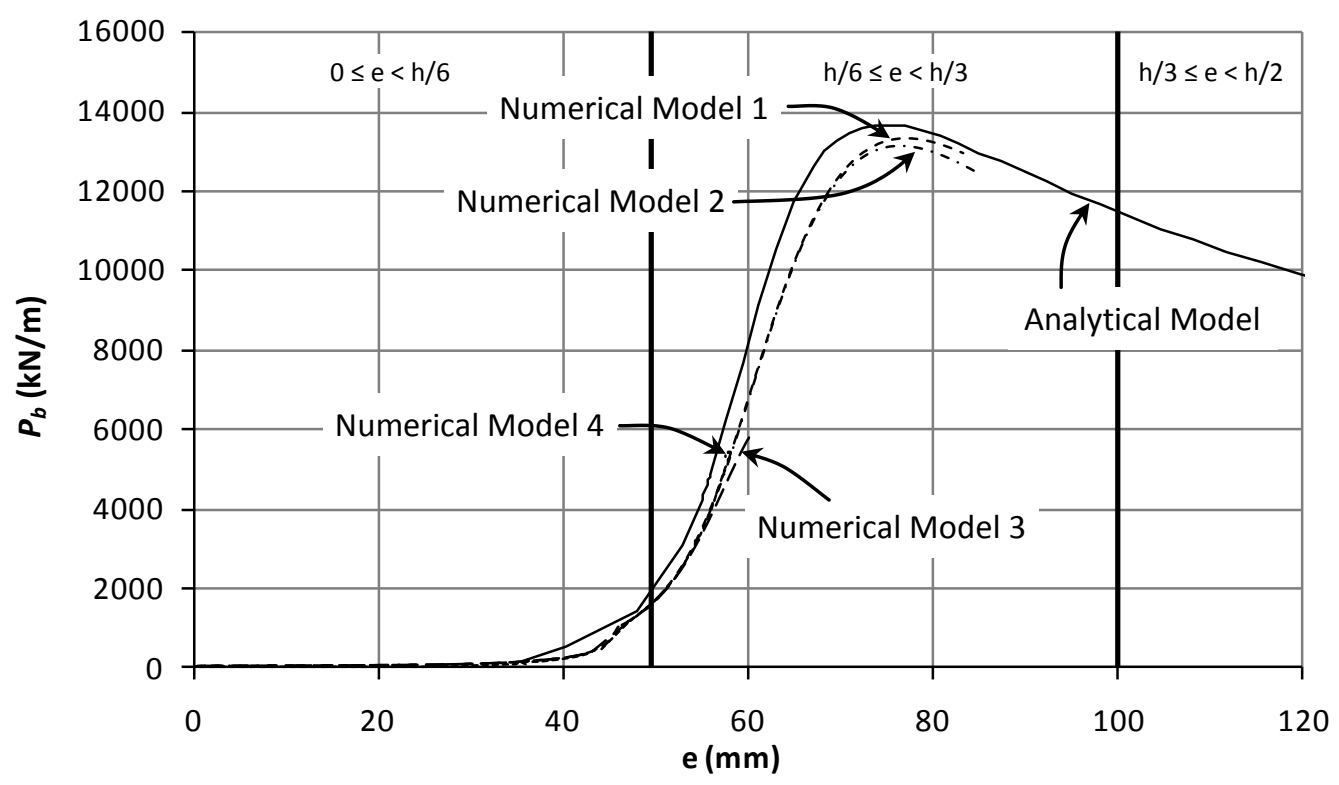

(b) Load versus eccentricity 


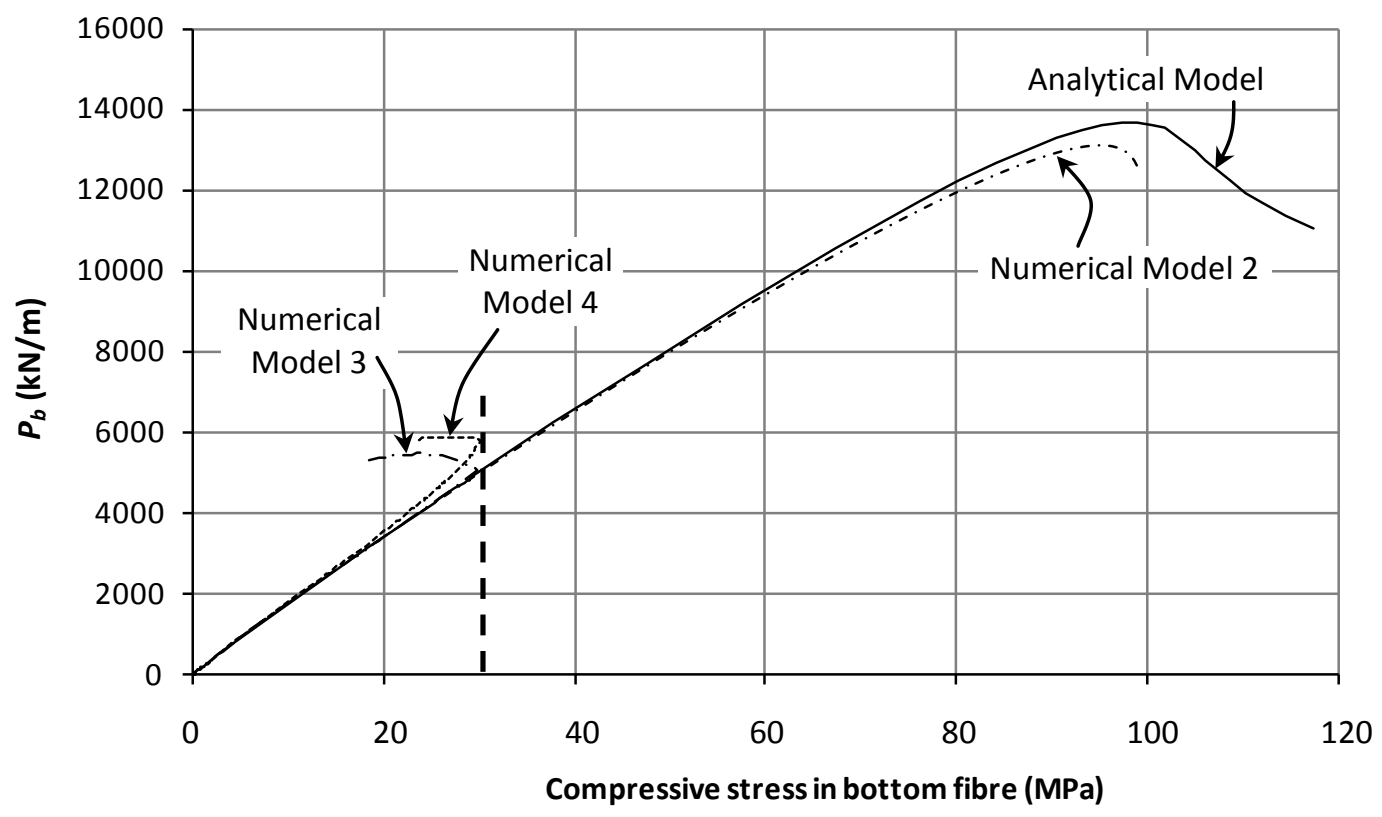

(c) Load versus bottom fibre stress

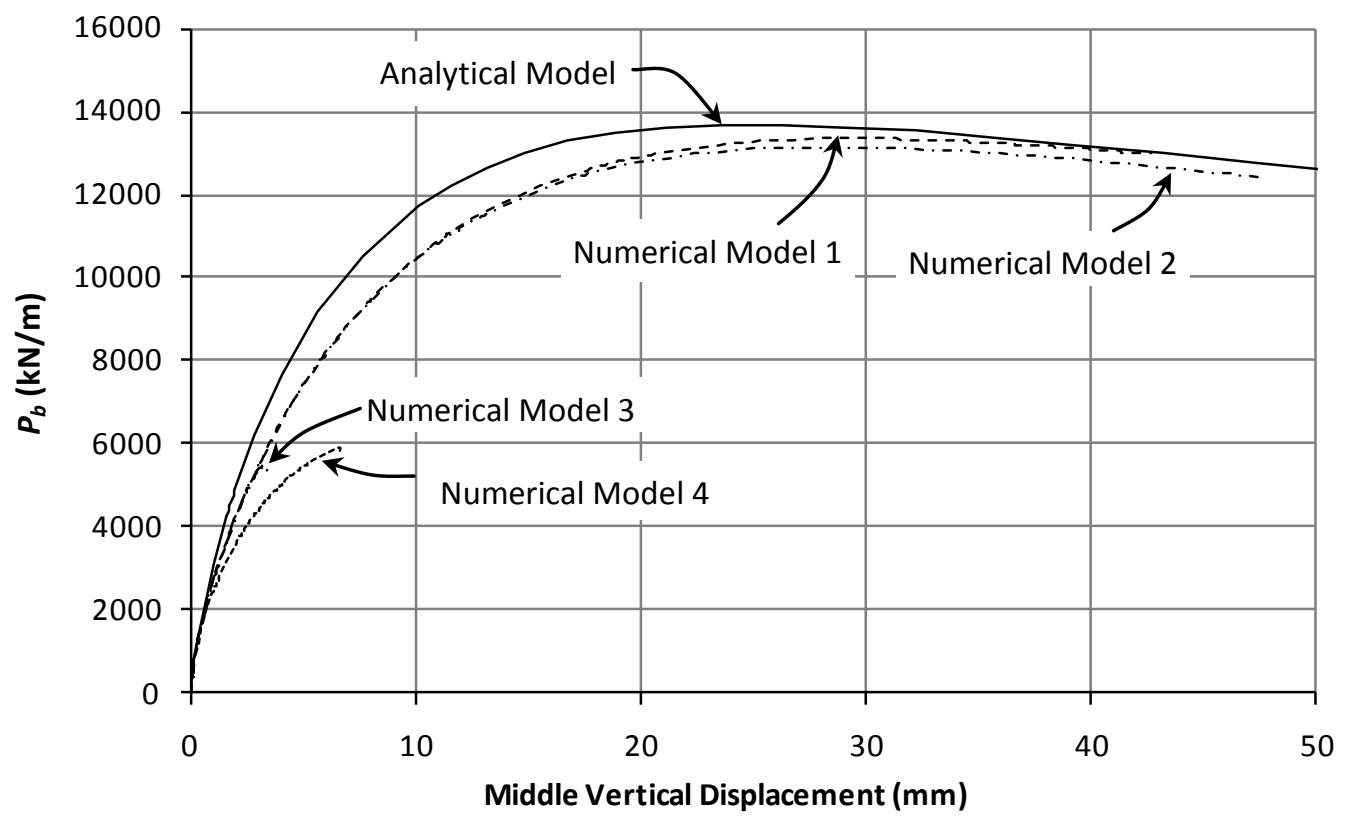

(d) Load versus buckle amplitude

Figure 6: Case study 1: Comparison between modified analytical model and NLFEA for $L_{g} / L_{p o}=0.1, f_{c k}=30 \mathrm{MPa}$ 


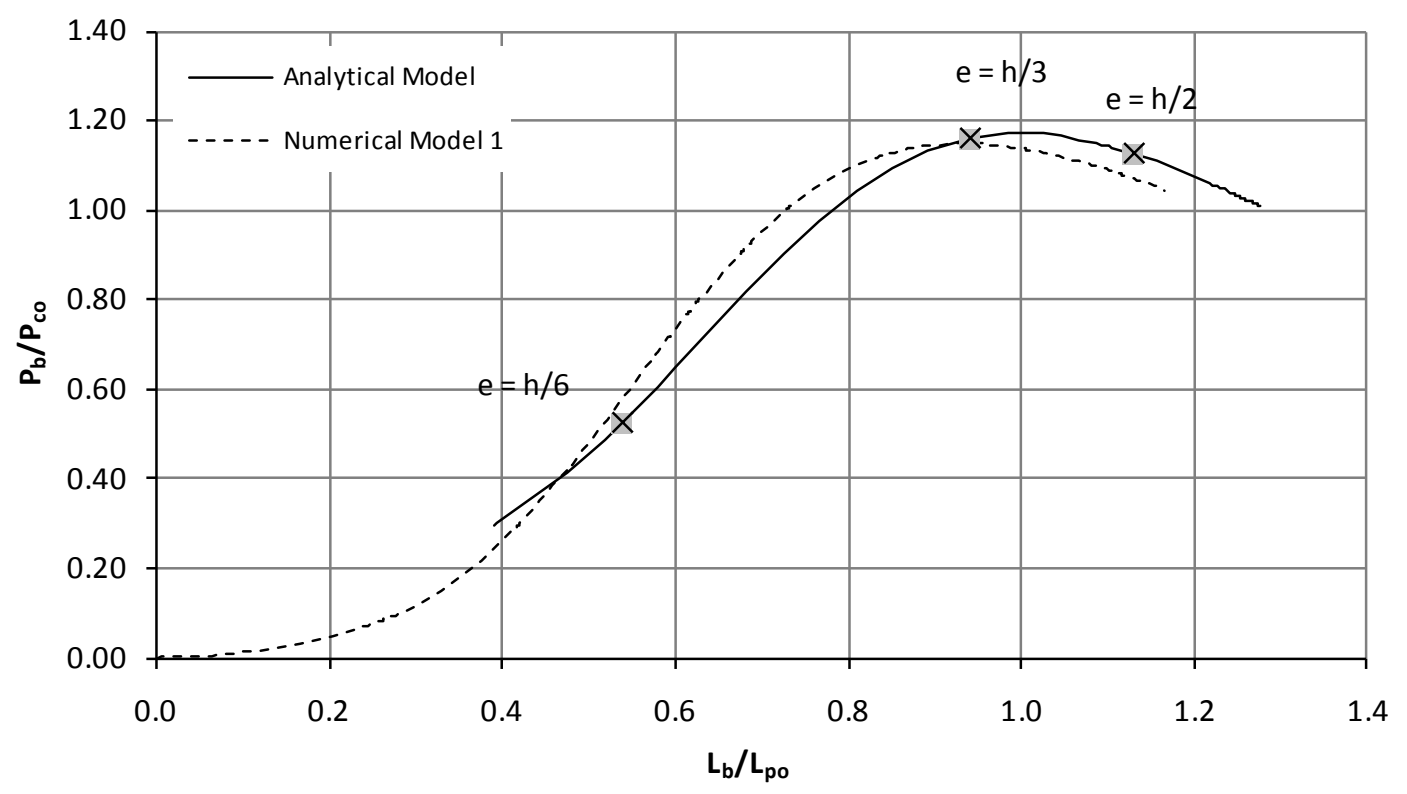

(a) Load versus buckle length

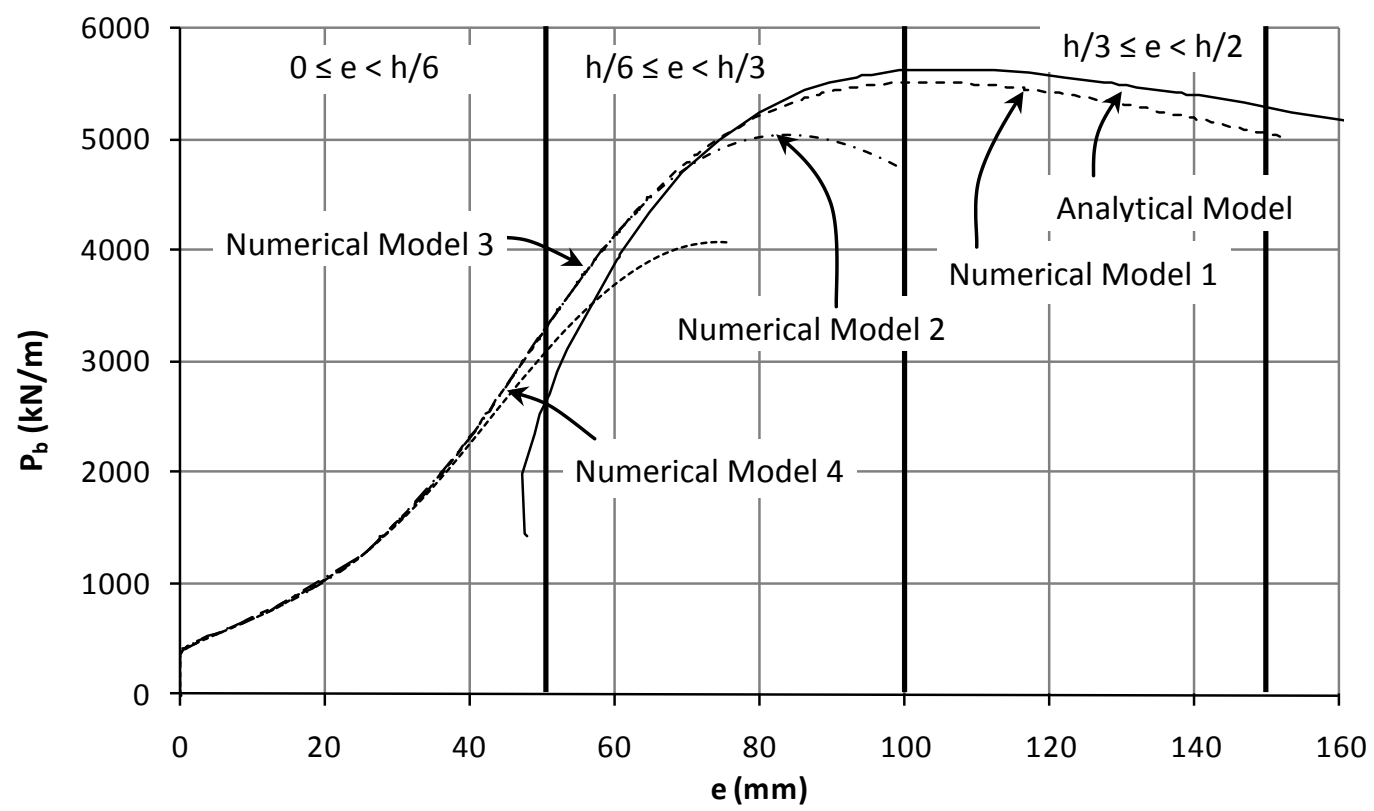

(b) Load versus eccentricity 


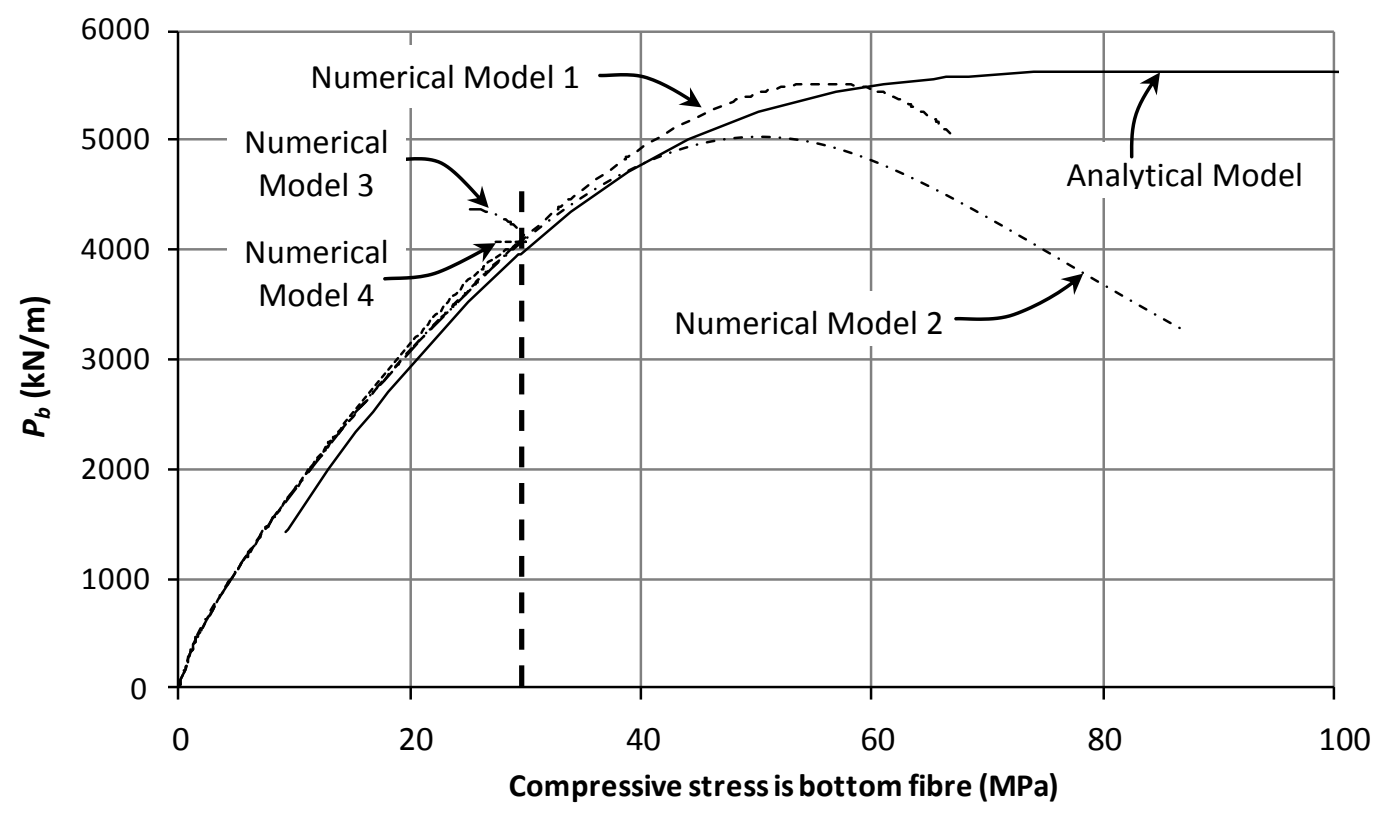

(c) Load versus bottom fibre stress

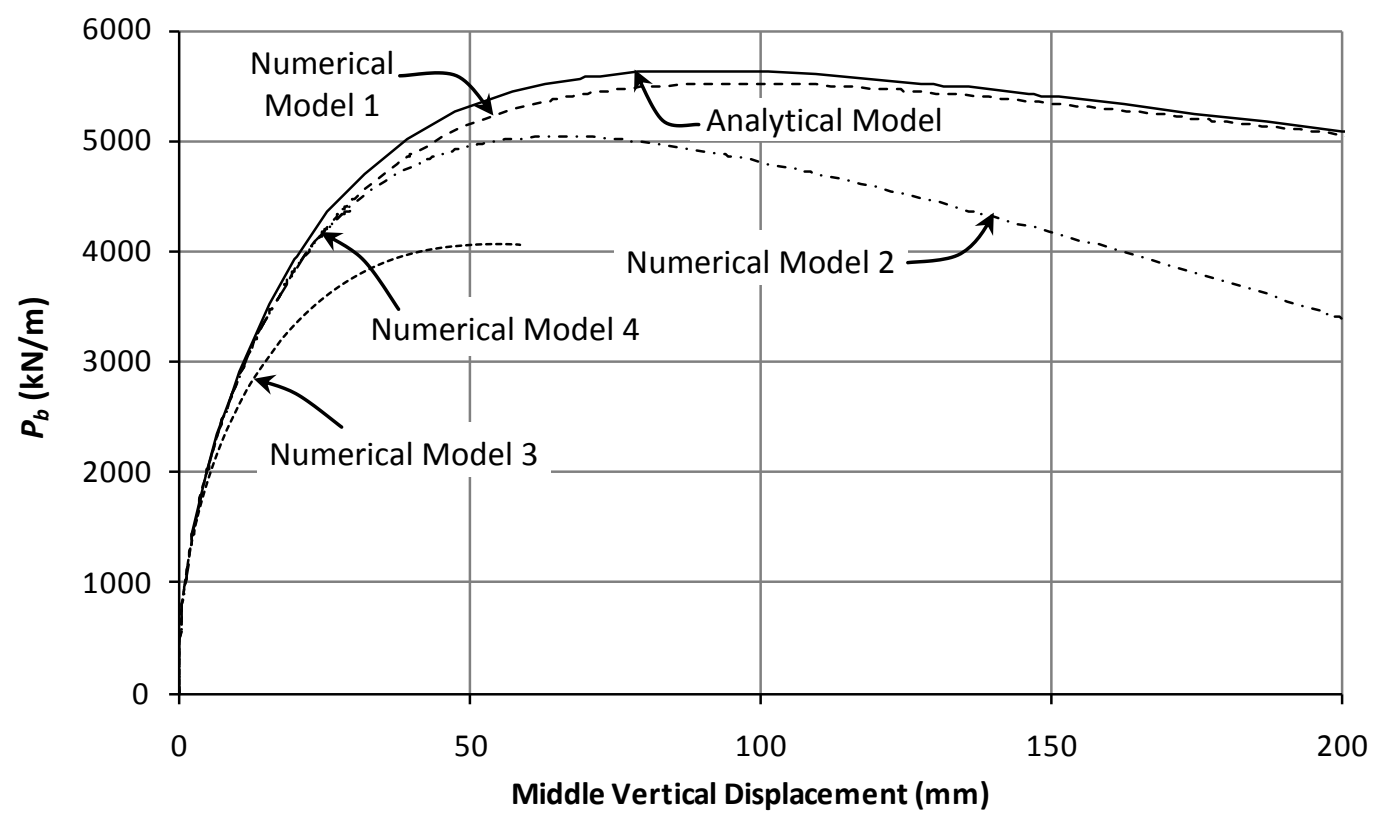

(d) Load versus buckle amplitude

Figure 7: Case study 2: comparison between modified analytical model and NLFEA for

$$
L_{g} / L_{p o}=0.4, f_{c k}=30 \mathrm{MPa}
$$




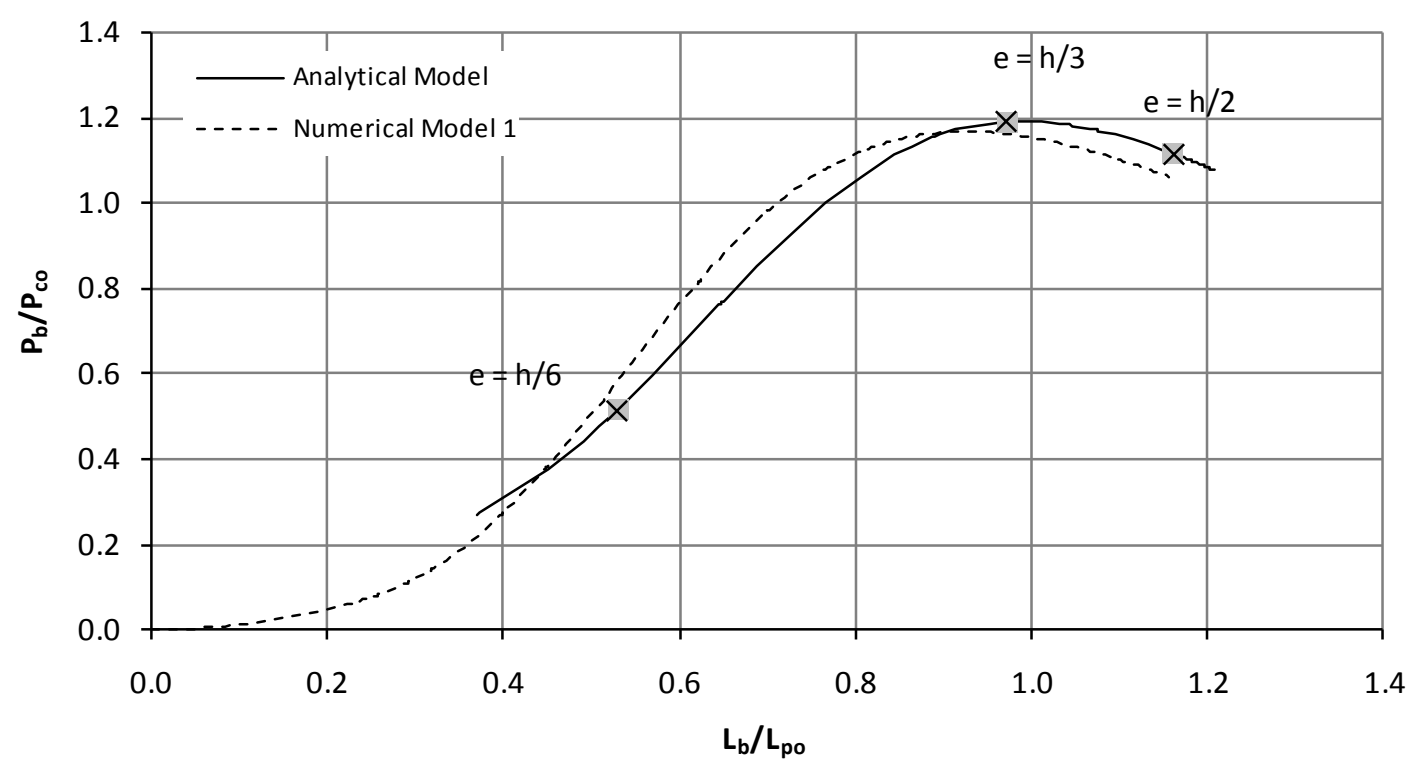

(a) Load versus buckle length

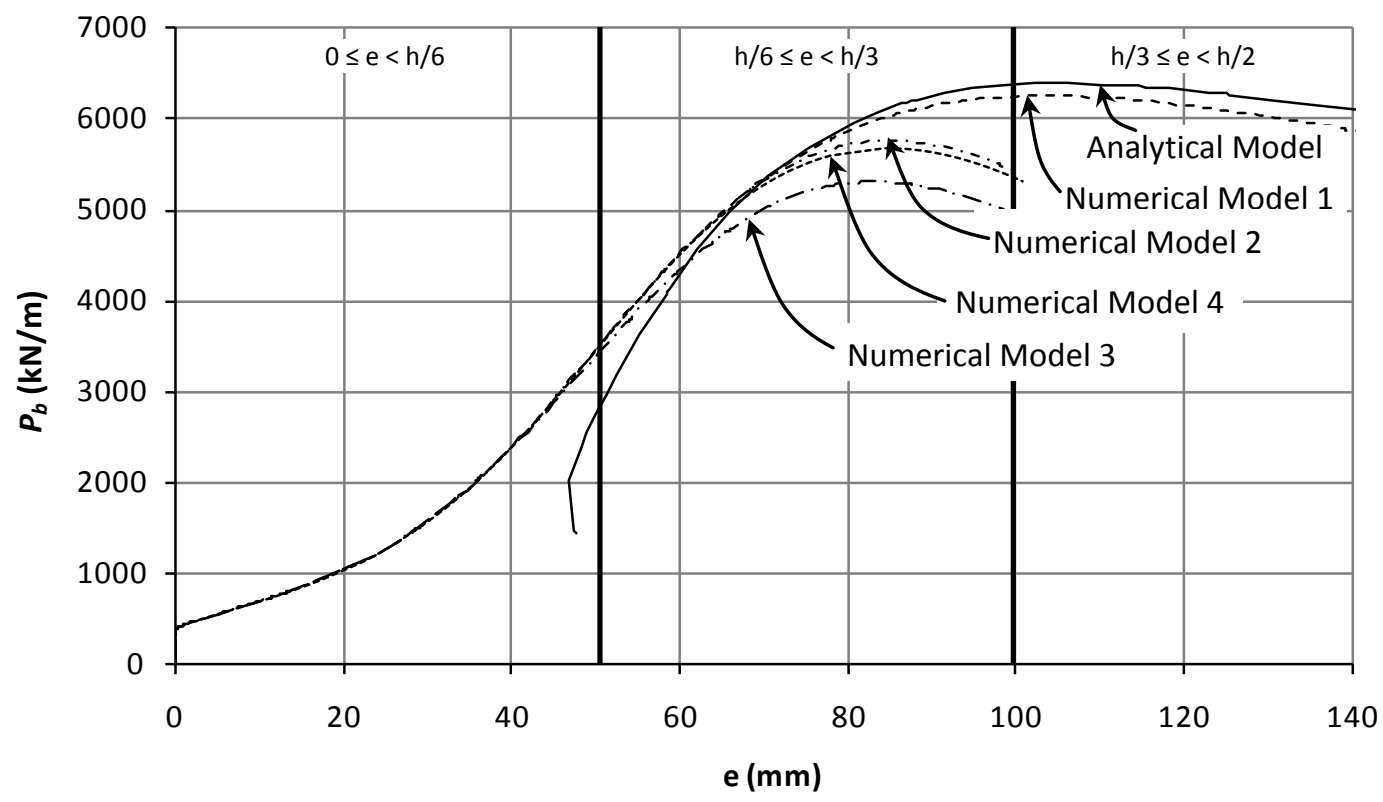

(b) Load versus eccentricity 


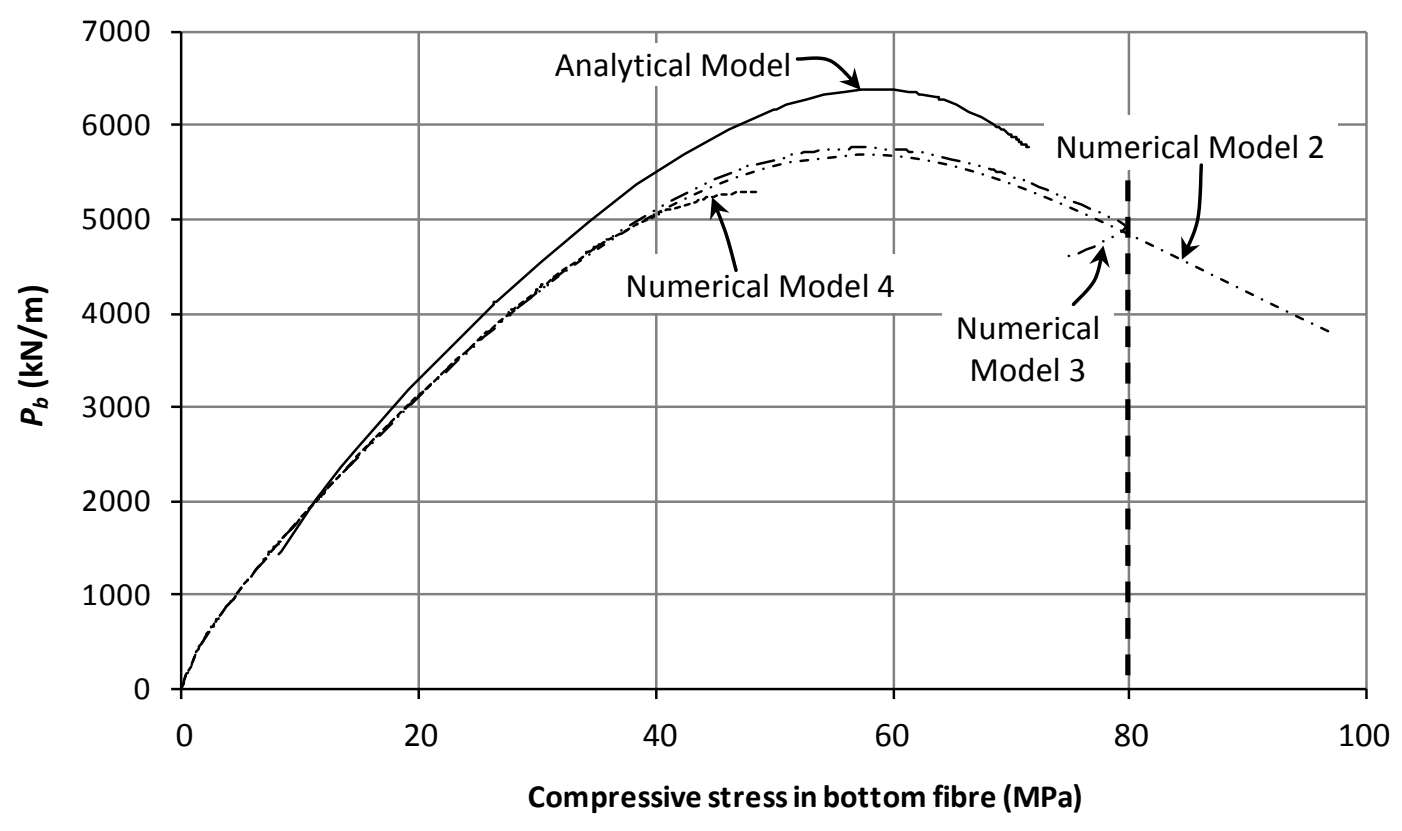

(c) Load versus bottom fibre stress

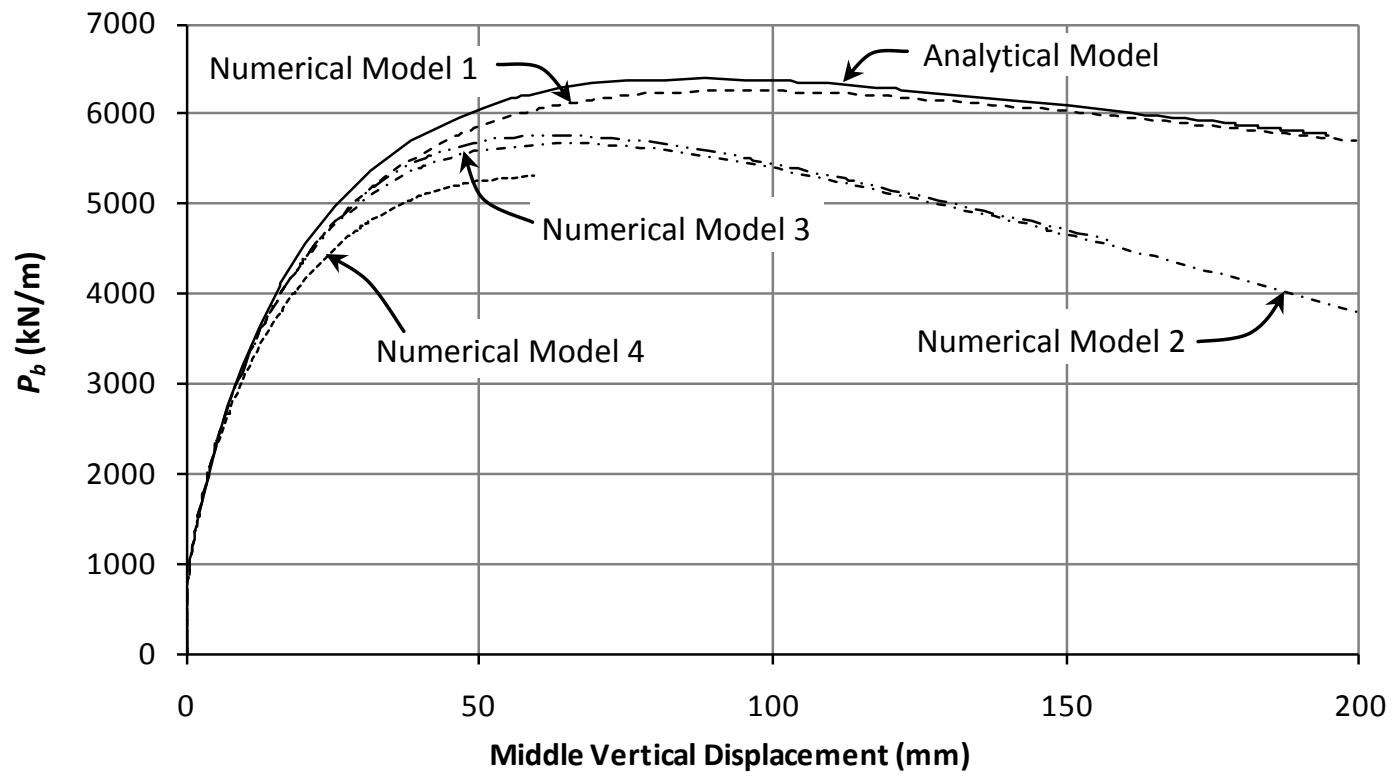

(d) Load versus buckle amplitude

Figure 8: Case study 3: Comparison between modified analytical model and NLFEA for $L_{g} / L_{p o}=0.4, f_{c k}=80 \mathrm{MPa}$ 


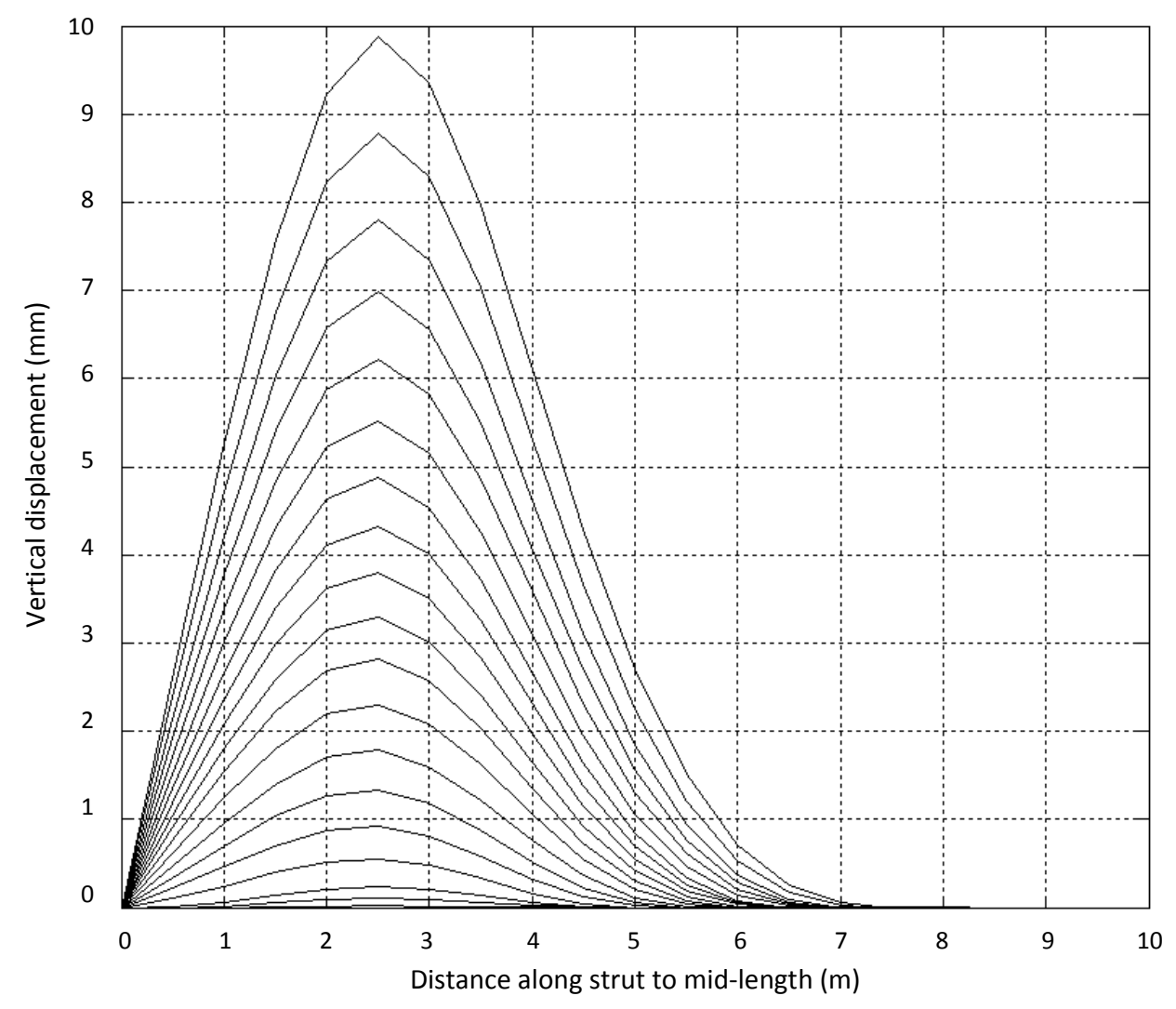

a) Propagation of the asymmetric $5 \mathrm{~m}$ profile for pin ended strut (buckling load reached at vertical displacement of $32 \mathrm{~mm}$ )

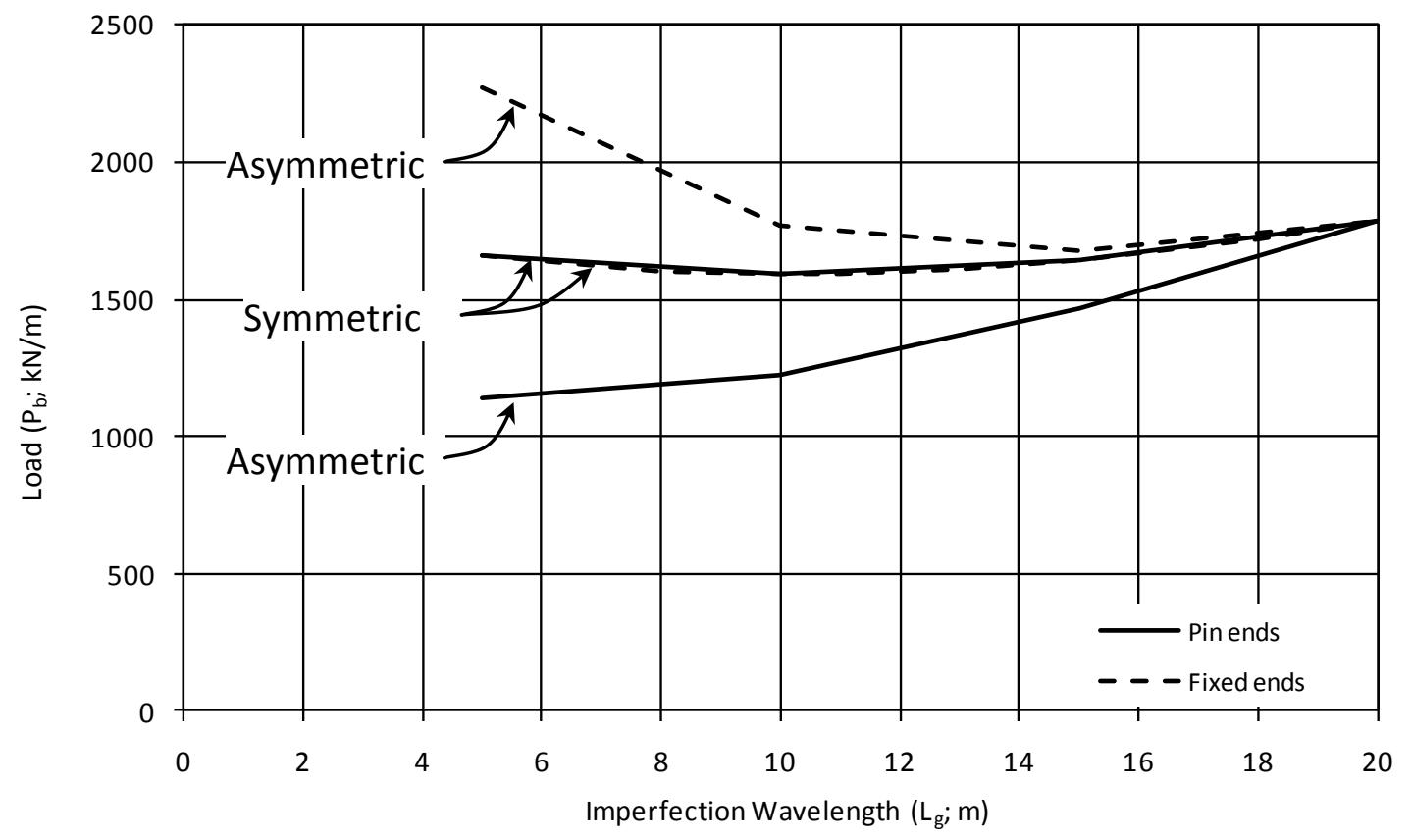

b) Effect of rotational restraint on the critical buckling load for symmetric and asymmetric imperfection profiles of varying length 
Figure 9: Buckling of struts with symmetric and asymmetric imperfection profiles (strut thickness $=200 \mathrm{~mm}, \mathrm{w}_{\mathrm{g}}=100 \mathrm{~mm}, \mathrm{~L}_{\mathrm{exc}}=20 \mathrm{~m}$ and $\mathrm{f}_{\mathrm{ck}}=30 \mathrm{MPa}$ ) 


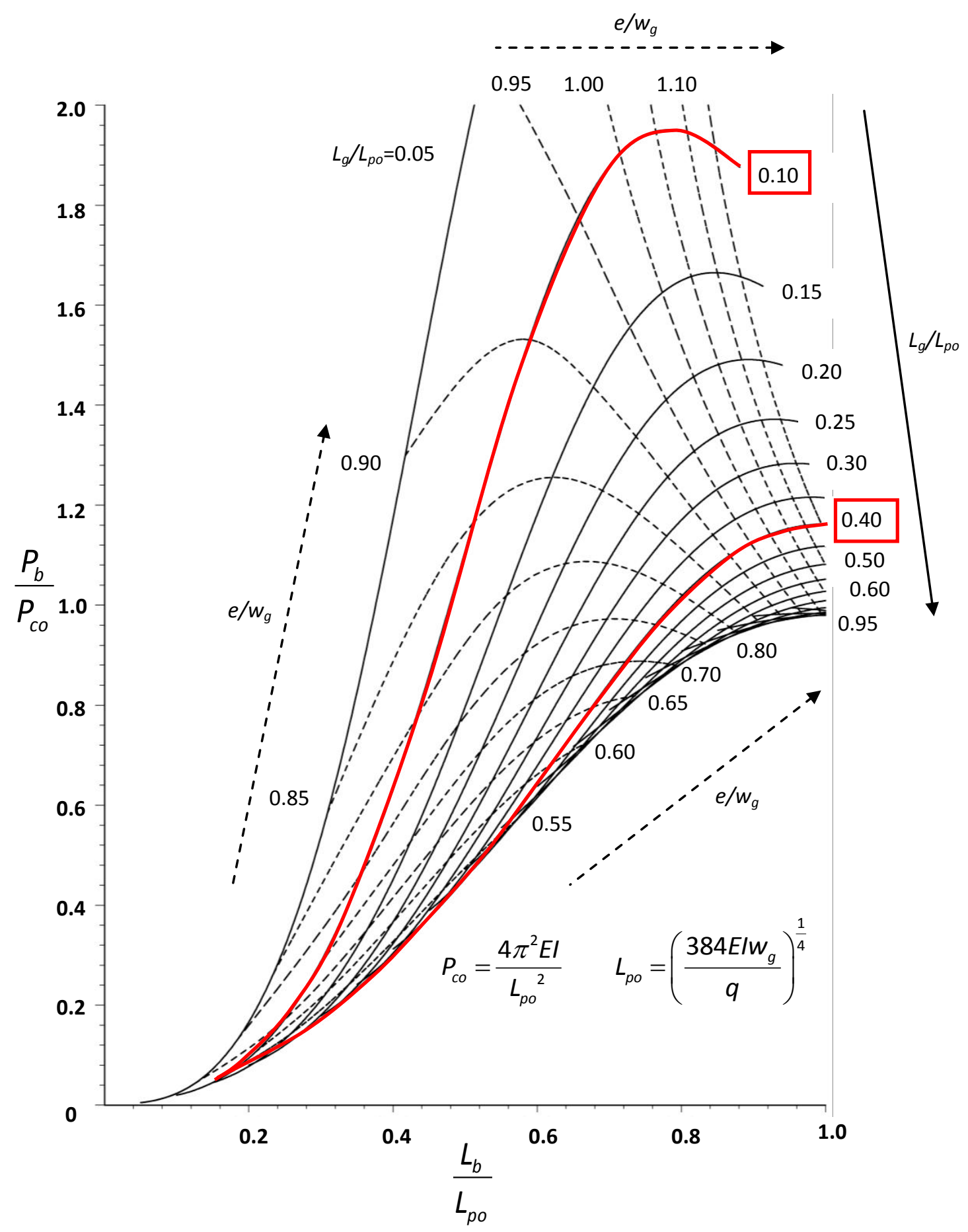

Figure 10: Design chart 


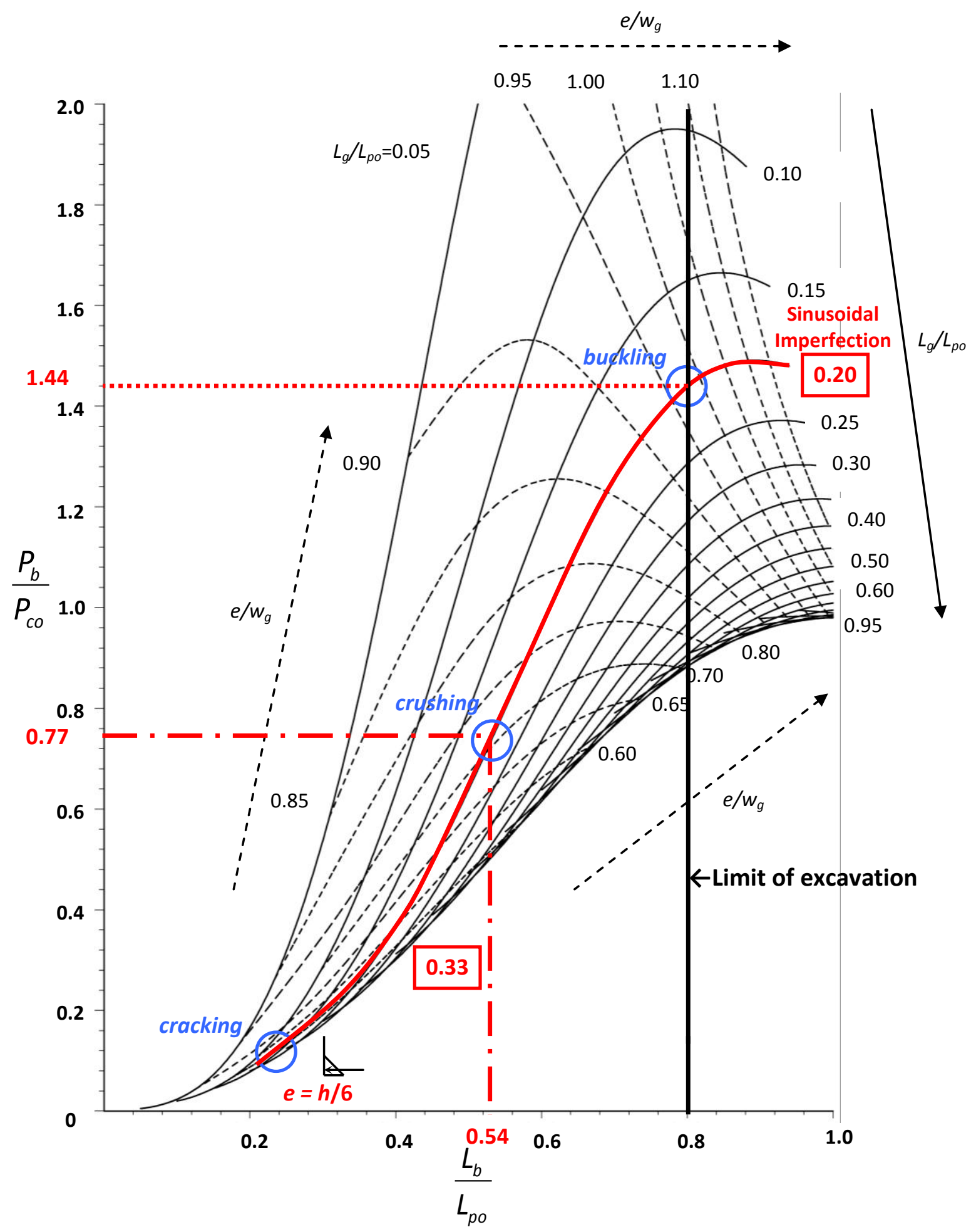

Figure 11: Illustration of use of design chart 


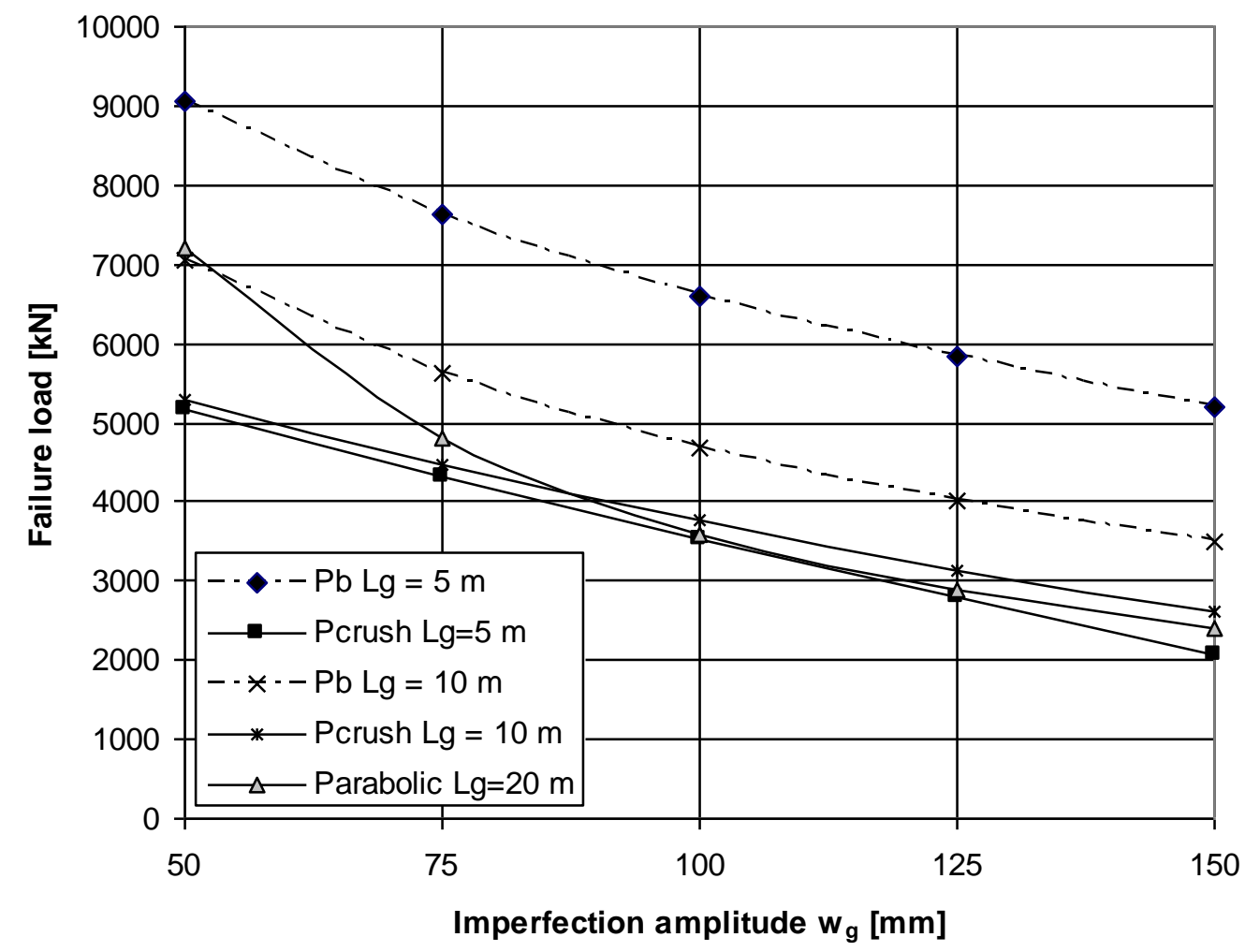

Figure 12: Influence of imperfection amplitude on a) buckling load and b) concrete crushing load ( $f_{c k}=30 \mathrm{MPa}$ ) for $300 \mathrm{~mm}$ thick strut with i) symmetrically positioned sinusoidal imperfections of length $5 \mathrm{~m}$ and $10 \mathrm{~m}$ and ii) parabolic imperfection. 